NBER WORKING PAPER SERIES

\title{
STRATEGIC INVOLUNTARY TEACHER TRANSFERS AND TEACHER PERFORMANCE: EXAMINING EQUITY AND EFFICIENCY
}

\author{
Jason A. Grissom \\ Susanna Loeb \\ Nathaniel Nakashima \\ Working Paper 19108 \\ http://www.nber.org/papers/w19108
}

\author{
NATIONAL BUREAU OF ECONOMIC RESEARCH \\ 1050 Massachusetts Avenue \\ Cambridge, MA 02138 \\ June 2013
}

This research was supported by a grant from the Institute of Education Sciences (R305A100286). We thank the leadership of the Miami-Dade County Public Schools for assistance with data collection and valuable discussions about policy implementation. We are especially appreciative to Gisela Feild, Claude Archer, and Sherry Krubitch at M-DCPS. Mari Muraki provided excellent data management. Mimi Engel, Helen Ladd, and seminar participants at the University of Kentucky gave helpful comments on an earlier draft of this manuscript. All errors are the responsibility of the authors. The views expressed herein are those of the authors and do not necessarily reflect the views of the National Bureau of Economic Research.

NBER working papers are circulated for discussion and comment purposes. They have not been peerreviewed or been subject to the review by the NBER Board of Directors that accompanies official NBER publications.

(C) 2013 by Jason A. Grissom, Susanna Loeb, and Nathaniel Nakashima. All rights reserved. Short sections of text, not to exceed two paragraphs, may be quoted without explicit permission provided that full credit, including (C) notice, is given to the source. 
Strategic Involuntary Teacher Transfers and Teacher Performance: Examining Equity and Efficiency

Jason A. Grissom, Susanna Loeb, and Nathaniel Nakashima

NBER Working Paper No. 19108

June 2013

JEL No. I21,J63

\begin{abstract}
Despite claims that school districts need flexibility in teacher assignment to allocate teachers more equitably across schools and improve district performance, the power to involuntarily transfer teachers across schools remains hotly contested. Little research has examined involuntary transfer policies or their effects on schools, teachers, or students. This article uses administrative data from Miami-Dade County Public Schools to investigate the implementation and effects of the district's involuntary transfer policy, including which schools transferred and received teachers, which teachers were transferred, what kinds of teachers replaced them in their former schools, and how their performance-as measured by their work absences and value-added in math and reading - compared before and after the transfer. We find that, under the policy, principals in the lowest-performing schools identified relatively low-performing teachers for transfer who, based on observable characteristics, would have been unlikely to leave on their own. Consistent with an equity improvement, we find that involuntarily transferred teachers were systematically moved to higher-performing schools. Efficiency impacts are mixed; although transferred teachers had nearly 2 fewer absences per year in their new schools, transferred teachers continued to have low value-added in their new schools.
\end{abstract}

Jason A. Grissom

PMB \#414

230 Appleton Place

Vanderbilt University

Nashville, TN 37203-5721

jason.grissom@ vanderbilt.edu

Susanna Loeb

524 CERAS, 520 Galvez Mall

Stanford University

Stanford, CA 94305

and NBER

sloeb@stanford.edu
Nathaniel Nakashima

Knight Management Center

655 Knight Way

Stanford, CA 94305-7298

nanakashima@stanford.edu 


\title{
Strategic Involuntary Teacher Transfers and Teacher Performance: Examining Equity and Efficiency
}

\author{
Jason A. Grissom \\ Vanderbilt University \\ Susanna Loeb \\ Nathaniel Nakashima \\ Stanford University
}

ABSTRACT

Despite claims that school districts need flexibility in teacher assignment to allocate teachers more equitably across schools and improve district performance, the power to involuntarily transfer teachers across schools remains hotly contested. Little research has examined involuntary transfer policies or their effects on schools, teachers, or students. This article uses administrative data from Miami-Dade County Public Schools to investigate the implementation and effects of the district's involuntary transfer policy, including which schools transferred and received teachers, which teachers were transferred, what kinds of teachers replaced them in their former schools, and how their performance-as measured by their work absences and valueadded in math and reading - compared before and after the transfer. We find that, under the policy, principals in the lowest-performing schools identified relatively low-performing teachers for transfer who, based on observable characteristics, would have been unlikely to leave on their

own. Consistent with an equity improvement, we find that involuntarily transferred teachers were systematically moved to higher-performing schools. Efficiency impacts are mixed; although transferred teachers had nearly 2 fewer absences per year in their new schools, transferred teachers continued to have low value-added in their new schools.

Districts and school leaders argue that having flexibility in assigning teachers to schools is necessary for improving both overall school quality and equity among schools (Cohen-Vogel \& Osborne-Lampkin, 2007; Levin, Mulhern, \& Schunck, 2005). One facet of such assignment flexibility is the authority to strategically transfer teachers to different schools, even if the teacher does not wish to move, to achieve a mix of personnel across schools that is better positioned to pursue district goals. Often, however, the collective bargaining agreement (CBA) with the local union prevents the district from engaging in strategic involuntary transfers. Instead, they limit involuntary moves to situations in which school enrollment declines result in 
the loss of teaching positions (referred to as excessing or surplussing), moves that are nonstrategic in the sense that seniority drives which teachers are moved and where they are placed in many districts (Koski \& Horng, 2007; National Council on Teacher Quality, 2010; Strunk \& Grissom, 2010). Some have argued that restrictions on strategic assignment are a key reason for lower performance among schools governed by more prescriptive collective bargaining agreements (Moe, 2009). These restrictions may harm disadvantaged students in particular because they rob districts of a tool for countering the vagaries of the voluntary sorting of better teachers towards higher-income, higher-achieving students, though the evidence on this relationship is mixed (Moe, 2009; Koski \& Horng, 2007; Lankford, Loeb, \& Wyckoff, 2002).

Calls for greater personnel assignment flexibility assume that, given the opportunity to strategically involuntarily transfer teachers among schools, districts would exercise this authority to improve the overall performance of the district, the fairness of the distribution of teaching quality within the district, or both (Levin, Mulhern, \& Schunck, 2005). There are numerous ways strategic use of involuntary transfers could have a positive impact on overall district performance or the equity of teaching resources. For example, if transfers help "match" teachers to schools where their particular set of skills will make a more positive impact, then we would expect the transfer to be efficiency-enhancing (Jackson, 2010). If transfers systematically move lowerperforming teachers out of low-performing schools, then the policy may positively impact equity, particularly if the teacher's replacement is more effective. Alternatively, if involuntary transfers result in worse matches of teacher skills and student needs, or if the transfer itself hurts teacher productivity, then potential gains to efficiency or equity will be undercut. No previous work has examined the effects of strategic use of involuntary transfer policies, leaving an 
evidentiary hole in discussions of the likely impacts of involuntary transfer policies for state or district policymakers.

This study contributes to our understanding of the policy levers districts can pull to affect the allocation of teaching quality by examining the involuntary transfer policy and its outcomes in the nation's fourth-largest school district, Miami-Dade County Public Schools (M-DCPS). Prior to the start of the 2009-10, 2010-11, and 2011-12 school years, M-DCPS exercised a clause in its CBA allowing for the transfer of teachers-identified by their principals-involuntarily within the district. Approximately 375 teachers were moved involuntarily over these three years. The district provided us with the involuntary transfer list in each year, which we merged with other district administrative data on schools, personnel, and students. We use this dataset to investigate how the transfer policy impacted the performance and distribution of teachers in the district.

Our analysis seeks to accomplish four main goals. First, we identify the characteristics of schools that utilized the involuntary transfer policy. Second, we document the patterns in involuntary moves, comparing the characteristics of the "sending" and "receiving" schools and the students in those schools. Third, we describe teachers who were chosen for involuntary transfer, both in comparison to teachers who did not move and to teachers who transferred voluntarily in the same years from the same schools. In particular, we examine characteristics of the teacher's job, such as whether it was in a tested grade and subject, and observable qualifications, such as years of experience. We also examine teacher absences, and, when available, their value-added to student achievement gains. Finally, we evaluate the impact of the district's involuntary transfer policy by assessing its effect on the distribution of teacher productivity across schools. Specifically, we compare teachers' work absences and job 
performance, measured by student test score gains, after an involuntary transfer both to their own pre-transfer measures and to those of the teachers who took their places in the sending schools.

We find that schools that utilized the involuntary transfer policy were, on average, larger, more likely to be middle and high schools, and served larger populations of low-income and African American students. They were also lower-performing, scoring a D on Florida’s accountability grading system, on average. We find no evidence that the involuntary transfer policy in M-DCPS was used to shuffle teachers from one low-performing school to another; receiving schools were rated approximately a B and had much higher math and reading achievement than sending schools, on average. Within schools that transferred at least one teacher, involuntarily transferred teachers tended to be somewhat lower in value-added (in math) and to be absent more often in the year preceding the transfer. They also tended to have experience and tenure profiles more similar to staying teachers than to voluntary exiters, suggesting that schools used the transfer policy to remove less productive teachers who were unlikely to leave otherwise. In their new schools, transferred teachers had fewer absences, suggesting a gain on one measure of productivity. Changes in value-added are more difficult to evaluate. While involuntarily transferred teachers look worse relative to their peers after transferring in terms of value-added to math achievement, this difference could be due either to a drop in performance or to an increase in the performance of the teachers' peer group, given that they are transferring to higher-performing schools. We do find evidence that teachers who replaced the involuntarily transferred teachers tended to be more productive. On the whole, the involuntary transfer policy appears to improve equity along the dimensions we examine, with some gains to efficiency as well. 


\section{MIAMI-DADE COUNTY PUBLIC SCHOOLS' INVOLUNTARY TRANSFER POLICY}

The M-DCPS CBA with the United Teachers of Dade, the local affiliate of the American Federation of Teachers, creates the framework governing teacher transfers in the district. According to Article XII, Section 8 of the CBA, the district may involuntarily transfer teachers across schools "when deemed in the best interest of the school system" (M-DCPS/UTD Successor Contract, 2009; NCTQ, 2009). The vagueness in this provision gives district administrators discretion—provided the transfers can be justified as promoting the district's interests - over the use of involuntary teacher transfers. This kind of statutory discretion is not uncommon; a recent analysis of CBAs throughout Florida found that a relatively large fraction of contracts (36 percent) provide administrators some discretion over involuntary transfers (CohenVogel \& Osborne-Lampkin, 2007), though this authority often goes unexercised. ${ }^{1}$

Although the district had involuntarily transferred teachers in more isolated cases in earlier years, M-DCPS first involuntarily transferred teachers on a large scale prior to the 200910 school year and then involuntarily transferred teachers again just prior to the following two school years. According to members of the M-DCPS central administration, the initial decision to make broader use of the involuntary transfer provision resulted from a number of factors, including the hiring of a new superintendent who brought a heightened focus on teacher quality

\footnotetext{
${ }^{1}$ It is difficult to know how common strategic involuntary transfers are nationwide, but the frequency likely is small. Results from the nationally representative Teacher Follow-up Survey run by the National Center for Education Statistics suggest that in 2009, 11 percent of teachers who changed schools did so because their contract at their prior school was not renewed (Keigher, 2010). Some of these teachers, however, would be considered dismissals rehired in other districts. Others would be a consequence of excessing or reductions-in-force. In these instances, CBAs typically require that districts take seniority into account when moving teachers by giving more senior teachers first choice over available positions, for example (Cohen-Vogel \& Osborne-Lampkin, 2007), likely making many such moves nonstrategic.
} 
and increased pressure from Florida's new Differentiated Accountability system to intervene quickly in the lowest-performing schools to increase student achievement. ${ }^{2}$

For each school year, the implementation of transfers proceeded generally as follows: in the months leading up, regional administrators—each school in M-DCPS is overseen by one of five (formerly six) regional offices which in turn report to the central administration—solicited from principals the names of teachers for whom a move would be in the best interest of the school system. Principals provided regional administrators with the lists, which they then forwarded to the Instructional Staffing division in the district central office. Instructional Staffing sought a new placement for each teacher, taking into account the availability of openings in a subject area in which the teacher was certified, the staffing needs of receiving schools, and, in some cases, input from regional administrators. ${ }^{3}$ Receiving schools had no say in the placement. In each year, transferred teachers were notified of the transfers and their new placements at the very end of the summer—in many cases not until the week before the start of school—but were in place in their new schools by the start of classes. ${ }^{4}$

Several additional details about the implementation of the transfer policy are relevant for our analysis. The first is the establishment of the Education Transformation Office (ETO) in 2010 as a hybrid "region" in the district (the others are geographic) to oversee and support schools designated by the Florida Department of Education (FLDOE) as "persistently lowest-

\footnotetext{
${ }^{2}$ Source: Authors' personal communications, November 2012. Alberto Carvalho became Superintendent of MDCPS in September 2008. Piloted in 2008, Florida's Differentiated Accountability plan and its accompanying supports and interventions were scaled up statewide as a result of legislation signed in June 2009.

${ }^{3}$ Source: Authors' personal communications with officials from M-DCPS Human Resources, August 2011 and May 2012. Regional office input might include, for example, requests not to transfer teachers into schools that had received involuntary transfers in a prior year.

${ }^{4}$ According to M-DCPS Human Resources, a handful of transferred teachers could be shuffled again at the start of a school year because of enrollment fluctuations at the receiving school.
} 
achieving." ${ }^{5}$ Whereas the geographic regions worked with principals on involuntary transfers in the first year (2009-10), for the remaining two years, the district concentrated the option to initiate a transfer among ETO schools, all of which were implementing strategies to improve teacher quality and some of which were "turnaround” schools with explicit strategies for changing the composition of the instructional staff. Given central office expectations that involuntary transfers would be concentrated among low-performing schools, we would not expect much use among higher-achieving schools, particularly following the creation of the ETO, but this assumption can be verified in administrative data.

Second, the district did not have formally articulated placement rules for teachers chosen for transfer. In theory, an absence of such rules could mean that a teacher transferred out of one low-performing school could simply be moved to another low-performing school. Informally, however, Instructional Staffing personnel were instructed not to place involuntarily transferred teachers in low-performing schools. ${ }^{6}$ Again, we can assess fidelity to this directive using administrative data.

Third, in schools in which involuntary transfers were an option, principals had discretion over both whether to nominate teachers for transfer and which teachers to nominate. According to conversations with M-DCPS central and regional administrators, principals were not given explicit criteria regarding what types of transfers would be in "the best interest of the school system.” Principals could choose teachers low in student test score growth or on another performance indicator, or they could, in theory, choose teachers who did not "gel” with other staff or who they thought might fit better in another school environment. These choices were

\footnotetext{
${ }^{5}$ Initially, the ETO oversaw 19 schools through a School Improvement Grant administered by FLDOE. In 2011, ETO's scope was expanded to 26 schools, then 66 schools in its third year. Information about the ETO is available at http://eto.dadeschools.net/aboutus.htm.

${ }^{6}$ Source: Authors’ personal communications with officials from M-DCPS Human Resources, February 2012.
} 
made with informal input from regional administrators in the sense that regional staff work closely with principals on an ongoing basis on teacher support, development, and evaluation and thus were likely to have had numerous conversations about particular teachers prior to any formal involuntary transfer process, but they exercised no formal "veto" over principals' choices. ${ }^{7}$ The discretion afforded principals in the involuntary transfer process makes examining the characteristics of the teachers transferred under the policy especially worthwhile.

\section{HOW INVOLUNTARY TRANSFERS COULD IMPACT EFFICIENCY AND EQUITY}

To understand the potential impacts of the involuntary teacher transfer policy, it is useful to consider the motivations of teachers, principals, and the district and what those motivations predict about their behavior. Ultimately, we are interested in the potential of an involuntary transfer policy to help districts pursue two broad goals. The first is efficiency, or increasing overall district performance at relatively little cost. So long as the transfer policy imposes few resource costs on the district-i.e., marginal administrative costs, no implications for teacher pay—any change in efficiency due to the policy is a function of how it impacts teacher and school productivity. The second is equity, or improving the fairness of the distribution of resources across schools. Although fairness or equity can be defined in different ways, we focus specifically on how the policy affected teacher productivity in the schools with the largest numbers of low-achieving students relative to other district schools.

The first behavioral consideration is how teachers respond to an involuntary transfer. Like many prior studies, we assume that teachers' labor market choices maximize total pecuniary and non-pecuniary benefits. Given no change in pecuniary benefits (e.g., salary) from an intra-

\footnotetext{
${ }^{7}$ Source: Authors' personal communications with M-DCPS regional leaders, November 2012.
} 
district transfer (as in M-DCPS), teachers made better off in terms of non-pecuniary benefits (i.e., working conditions) from an involuntary transfer will be more likely to stay, while those made worse off would be more likely to exit the system and seek employment elsewhere. Nonpecuniary benefits include those associated with the characteristics of the school and job placement and those associated with identification as an involuntarily transferred teacher (e.g., stigma).

The second behavioral consideration concerns how school principals respond to the opportunity to choose teachers for involuntary transfer. In a high-stakes school accountability context, a primary goal of principals may well be to improve student test outcomes by improving teacher performance, particularly as it affects student achievement in tested grades and subjects. Importantly, teacher performance can have multiple dimensions, some of which, like delivering high-quality instruction, affect student outcomes directly, and others—such as contributing to a positive school climate—affect students indirectly. Because changing the composition of the teaching faculty is one strategy for improving teacher performance, given the opportunity, a principal likely will choose to move a teacher out of the school if the principal expects that he or she will be able to hire a higher-performing replacement teacher than the one lost to the transfer. Novice teachers still in the probationary (pre-tenure) period can be moved out via non-renewal, so it is likely that principals' involuntary transfer choices will be concentrated among more experienced teachers.

Anticipating, to a certain extent, the responses of teachers and principals, district leaders decide how the involuntary transfer policy will be implemented. Implementation has many moving parts; we focus here on two central details: which schools should be given the opportunity to transfer teachers out and to which schools transferred teachers should be moved. 
Accountability is a strong motivator for the district. In many states, including Florida, the pressures for rapid school improvement are most acute for the district's lowest-performing schools. As one M-DCPS district official framed it, a high-performing school seeking to remove a low-performing teacher could take the time to document the poor performance and implement corrective action that could led to dismissal, but low-performing schools face pressures to turn around quickly. ${ }^{8}$ So while in theory the district might allow any school to involuntarily transfer a teacher, accountability pressures coupled with resource (e.g., staff time) and political constraints—including, in M-DCPS, the fact that moves must be justifiable as "in the best interest of the system,” which likely is easier in moving a low-performing teacher out of a lowperforming school—suggest that districts have good reasons to concentrate transfers in schools with large numbers of low-achieving students.

On the question of where transferred teachers should be moved, the district faces at least three considerations. The first is, again, state accountability. If principals are going to identify low-performing teachers to be transferred, relocating those teachers to other low-performing schools facing similar accountability pressures is not, from the district's perspective, beneficial. Moves to higher-performing schools with little chance of failing against accountability standards, however, may be beneficial in the aggregate, since, while potentially marginally negative for the receiving school, will be unlikely to result in accountability consequences. The second consideration is the potential for increasing the transferred teacher's own productivity by providing a better "match" in the new school for that teacher’s skills. Individual teachers likely have unique sets of attributes-e.g., instructional approaches, experiences working with particular student populations, cultural competencies—-to which some students, or types of

\footnotetext{
${ }^{8}$ Source: Authors’ communications with district and regional leadership, November 2012.
} 
students, are more responsive than others. Consistent with this idea, Jackson (2010) presents

evidence that a large fraction of observed teacher effectiveness among North Carolina teachers is attributable to match quality and that match quality tends to improve with voluntary moves. If districts are better able to match an individual teacher's skills to a school or student population than occurs through the typical hiring process that paired that teacher with his or her school, a transfer by the district could increase teacher productivity. For instance, a teacher's skills may lend themselves to working particularly well with English language learners (ELLs), which the district may learn via conversations with school leadership or analysis of administrative data. In this case, a move to a school with a larger population of ELL students may improve the teacherschool match and increase productivity. On the other hand, if districts do not have the capability to create better matches, teacher transfers would have no or even negative impacts on the productivity of transferred teachers. A third consideration that the district may face is the pressure from potential receiving schools not to accept teachers who are likely to be relatively less effective. If this pressure is too great, it may overwhelm the other considerations even if the first two factors would result in equity and efficiency benefits for the district.

\section{Efficiency}

The involuntary transfer of teachers would improve district efficiency if it increased district outputs without a comparable increase in district inputs. Because the policy simply moves teachers into open positions rather than dismissing them, district inputs in the aggregate are not directly affected. Thus, our efficiency analysis focuses on how the involuntary transfer policy affects teacher productivity. 
As just discussed, one mechanism whereby the involuntary transfer policy could improve teacher productivity is through a better match for transferred teachers that allows those teachers to be more effective than they were in their former schools. Secondarily, transferring those teachers out may allow the sending school to hire a teacher who matches better to that school as well. Of course, these effects may be offset if the receiving school could have hired a better (or better matched) teacher into the slot filled by the transfer.

Productivity may also be affected by changes in teacher effort, though the likely direction of this effect is unclear. The threat of a transfer could impact the effort of teachers at schools allowed to identify teachers for transfer. These effects could be positive if teachers see the transfer threat as a potential negative consequence that increased effort can help them avoid. Alternatively, the effects on effort could be negative if, for example, the transfer threat hurts teacher morale. Involuntary transfers can also affect the effort level of teachers chosen for transfer specifically, though again, the predicted direction is ambiguous. Transferred teachers may work harder if they see the transfer as a signal that they need to improve their performance or if they are relocated to a school environment that encourages extra effort because, for example, they are surrounded by more productive teacher peers (Jackson \& Bruegmann, 2009). In contrast, they may decrease their effort post-transfer if they find the transfer demoralizing or discouraging.

\section{Equity}

Involuntary transfers may also affect the fairness of the distribution of teacher quality or effectiveness within a district. Here the primary mechanism is clear. A robust literature on voluntary mobility patterns among teachers shows that the teacher labor market tends to sort 
more qualified teachers into schools with more advantaged students and low-performing teachers into schools with less advantaged students (e.g., Boyd, Lankford, Loeb, \& Wyckoff, 2005). A strategic involuntary transfer policy gives the district an opportunity to counteract this tendency. By redistributing effective and ineffective teachers across schools, district-initiated transfers can be used to increase the concentration of high-quality teachers in schools with less advantaged, lower-achieving students.

Of course, empirically, an involuntary transfer policy need not improve the distributional equity of teachers across schools if the district does not have the capacity to implement it strategically. Little equity improvement will occur if principals do not select low-performing teachers, or if the district moves low-performing teachers to other disadvantaged schools. Likewise, if teachers transferred out of low-performing schools are replaced with similarly or less effective teachers, the policy will not improve equity.

In sum, while an involuntary transfer policy has the potential to further district goals along efficiency and equity lines, there are numerous reasons to expect that it may be ineffective or even deleterious. This topic is thus ripe for empirical examination. The next section details the data we use to assess the involuntary transfer policy in M-DCPS.

\section{DATA}

We conduct our analyses using rich administrative databases on students, staff, and schools in Miami Dade County Public Schools (M-DCPS), the fourth largest public school district in the United States. M-DCPS serves approximately 380,000 students, with an ethnic distribution of about 9 percent white, 26 percent black, and 63 percent Hispanic students. Over 60 percent of students are eligible for subsidized lunch, and 15 percent are English language 
learners. Instruction is delivered by a teacher force of around 23,500 across approximately 400 schools.

To facilitate our analysis of transfers, M-DCPS human resources provided us with lists of all teachers who were involuntarily transferred to different schools within the district in the summers prior to the 2009-10, 2010-11, and 2011-12 academic years. A concern with using lists of teachers actually transferred is that it may be incomplete in the sense that it is missing teachers identified for transfer by principals but were never moved, either because central or regional staff disagreed with the principal's choice or because some teachers, informed of the impending transfer and their new assignment, left the system altogether. Several factors help alleviate concern about these potential sources of missing data. First, as previously discussed, central and regional staff gave informal input into principals' decisions but exercised no formal approval. Second, teachers were not notified that they were being transferred until immediately prior to the start of the school year, leaving them little time to secure employment teaching in another district. Moreover, because Instructional Staffing operated on an expectation that teachers were not to be transferred into low-performing schools, teachers may have perceived that working conditions in their newly assigned schools would be better, making it less likely that they would wish to avoid the transfer (even if they would have preferred ex ante to avoid involuntary transfer status $)^{9}$

We linked the lists of involuntary transfers with longitudinal administrative data containing information about school, staff, and student characteristics, which the district also provided to us. School characteristics include enrollment size, school level, student racial/ethnic

\footnotetext{
${ }^{9}$ Additionally, teachers who were moved tended to be relatively experienced, and research shows that attrition propensities decrease with experience (Guarino, Santibañez, \& Daley, 2006). Indeed, Instructional Staffing personnel could recall only "one or two" instances that involuntarily transferred teachers quit prior to school over the three years of implementation (Source: Authors’ communications, November, 2012).
} 
composition, proportion of subsidized lunch eligible students, and school performance ratings based on Florida's accountability system. Staff characteristics include teacher and principal gender, ethnicity, age, number of years in the district and current position, and academic degree. The district also provided us with teacher absence data for some years. Student characteristics include scores on the Florida Comprehensive Assessment Test (FCAT), absence and disciplinary records, and demographic information, including gender, race, subsidized lunch status, and whether the student is limited English proficient. We link student records to both their teachers and classrooms.

Table 1 presents summary statistics for schools that utilized the involuntary transfer policy in 2009-10, 2010-11, and 2011-12 and for the teachers who were involuntarily transferred from those schools. Of the 73 schools transferring at least one teacher in at least one of these years, 45 percent are high schools, 19 percent are elementary schools, 25 percent are middle schools, and 11 percent are K-8 schools. The student population in these schools is 72 percent African American, 26 percent Hispanic, and 83 percent subsidized lunch-eligible. According to Florida's school accountability system, the schools are, on average, very low-performing; though the grades range from 1 (F) to 5 (A), the average is 2.2, or approximately a D.

Across the three years in our study, the schools involuntarily transferred 375 teachers, approximately 10 percent of all teacher transfers in the district during that time period. Of these teachers, 72 percent were female, 59 percent were African American, and 21 percent were Hispanic. They were also a relatively experienced group, with 60 percent having five or more years of experience and only 8 percent having one year or less. In addition, 51 percent held a bachelor's degree as the highest degree, 35 percent held a master's degree, and 4 percent held a doctorate. 


\section{ANALYSIS AND RESULTS}

Our analysis seeks to understand the equity and efficiency implications of the district's involuntary transfer policy by answering four research questions: (1) Which schools involuntarily transferred teachers? (2) Where were involuntarily transferred teachers moved? Which teachers were involuntarily transferred, and who replaced them? (4) Did involuntary transfers affect teacher productivity? For each research question, we employ a number of empirical approaches. In what follows, we describe the analytical approach and the results separately for each question. For the first and second questions we are particularly interested in whether lower-performing schools make greater use of involuntary transfers and whether higherperforming schools are more likely to receive involuntary transfers because equity gains resulting from the policy most likely would be driven by the combination of these mechanisms. For the third question we are especially interested in whether lower-performing teachers within the transferring schools are more likely to be transferred because, again, equity gains rely on low-performing schools moving out their less effective teachers. Similarly, we are interested in whether they were replaced by more or less effective teachers. For the final question, we focus on whether transferring teachers perform better following transfer, as this is a potentially important mechanism for efficiency gains.

\section{Which Schools Involuntarily Transferred Teachers?}

The first step in assessing the potential equity impacts of the involuntary transfer policy is to identify the characteristics of the schools that transferred teachers. As Table 1 shows, 73 of the district's roughly 370 schools utilized the involuntary transfer option during the three-year 
window we examine. To assess whether schools that made use of the policy differed from those that did not, we first conduct $t$-tests of differences in their observable characteristics. This comparison appears in the right-most columns of Table 1.

Schools that utilized the policy were far lower-achieving as reflected by FCAT math and reading scores and proficiency levels and accountability grades. Only 48 percent of students in transferring schools achieved proficiency in math and only 27 percent in reading, compared to 65 and 61 percent, respectively, in non-transferring schools, reflecting score differences between the two types of schools of about half a standard deviation in both subjects. Similarly, the average state accountability grade for schools using the involuntary transfer policy was 2.2 (D), compared with an accountability grade of 4.3 (or about a B) for schools that did not use the policy.

Among other characteristics, schools that utilized the involuntary transfer policy were, on average, larger and served a higher percentage of black and subsidized lunch-eligible students (our proxy for low-income) than did non-utilizing schools. The difference in school size follows from the fact that high schools, which have larger enrollments than other school levels, accounted for 45 percent of the schools that utilized the involuntary transfer policy. In short, the typical school utilizing the involuntary transfer policy was a low-performing high school with a relatively high proportion of black and low-income students.

Table 1 also shows characteristics of principals and teachers. Perhaps reflecting higher turnover rates in low-achieving schools, the principals who involuntarily transferred teachers had served as a principal for an average of less than two years, compared to more than four years for principals who did not involuntarily transfer teachers. Principals who utilized the involuntary transfer policy also included a greater proportion of male and black principals than their 
colleagues who did not utilize the policy. Teachers in those schools were more likely to be male and black, less likely to be Hispanic, and to have fewer years of experience both total and in the current position. These teachers were also lower in value-added, on average, though also had lower absence rates (8.5 vs. 9.7 days).

We next employ logit models to predict the likelihood that a school uses the involuntary transfer policy as a function of school and principal characteristics. The goal of the multivariate approach is to isolate whether lower-performing schools are more likely to transfer teachers even after controlling for other factors. Equation 1 describes the model:

$$
\operatorname{Pr}(\text { uses involuntary transfer policy })_{s y}=\frac{e^{f}}{1+e^{f}}
$$

where

$$
f=\beta_{0}+S_{s y} \beta_{1}+P_{s y} \beta_{2}+\delta_{y}+\varepsilon_{s y}
$$

The probability that school $s$, in year $y$, utilized the involuntary transfer policy is a function of school characteristics $S_{s y}$ (enrollment size, percentage of students eligible for subsidized lunch, and percentage of students who are black ${ }^{10}$, school level, school average combined standardized FCAT math and reading score), principal characteristics $P_{s y}$ (gender, black, Hispanic, total experience in the district, years in current position, ${ }^{11}$ highest academic degree), school year indicator variables $\delta_{y}$, and a random error term $\varepsilon_{s y}$. We cluster standard errors at the school level.

\footnotetext{
${ }^{10}$ Because the correlation between percent black and percent Hispanic is approximately -0.9 across schools, percent Hispanic is omitted from our models.

${ }^{11}$ In the administrative files, years in current position measures the number of years in the same job code and school level combination, not necessarily the years in the same school. In other words, a principal who works in one high school for three years then transfers to another high school for two years will have five years in the current position. M-DCPS personnel files do not track years in same school.
} 
Table 2 shows these results, with coefficients expressed as odds ratios. Column 1 includes school characteristics only. Results show that schools were less likely to utilize the involuntary transfer policy as test scores increased, even conditional on other student characteristics. Moreover, across models, larger schools that served a higher population of black and subsidized lunch-eligible students were significantly more likely to involuntarily transfer teachers. K-8, middle, and high schools were all significantly more likely than elementary schools to utilize the involuntary transfer policy, with high school being an especially important predictor.

Column 2 shows that these relationships cannot be explained by characteristics of the school's principal. Few principal characteristics were associated with the probability that a school involuntarily transfers teachers, though female and longer-serving principals were less likely to utilize transfers, all else equal. ${ }^{12}$

\section{Where Were Involuntarily Transferred Teachers Moved?}

Having established that low-performing schools with larger numbers of disadvantaged students were more likely to transfer students, the next question in determining whether the involuntary transfer policy made the distribution of teacher quality more equitable is what kinds of schools received transferred teachers. To assess patterns in the involuntary movement of teachers, we use $t$-tests to compare characteristics of schools that involuntarily transfer teachers and schools that receive teachers who have been involuntarily transferred. We refer to schools

\footnotetext{
${ }^{12}$ We also ran a version of the model that included indicator variables for a principal's years of experience in the current position. Estimates showed that principals new to a school (first or second year) were the most likely to utilize the transfer policy, with the probability dropping significantly for those with 2-3 and 4-5 years of experience. The odds of utilizing the policy for a beginning principal were about 20 times higher than a principal with $6+$ years of experience.
} 
that involuntarily transferred at least one teacher as "sending" schools and schools where these teachers are placed after the transfer as “receiving” schools. Table 3 presents comparisons of characteristics of sending and receiving schools from the year of the transfer.

The table shows that teachers were involuntarily transferred to much different school environments than the ones they left, on average. In particular, while transferred teachers were more likely to come from high schools, elementary schools were the most likely to receive transfers. Compared to sending schools, receiving schools had fewer black (72 percent to 32 percent) and free or reduced price lunch-eligible (83 percent to 72 percent) students, and higher numbers of Hispanic (26 percent to 57 percent) and limited English proficient students (11 percent to 16 percent).

In M-DCPS, Hispanic students, the district’s largest ethnic group, are more concentrated in high-achieving schools. Consistent with this observation, the table shows that involuntarily transferred teachers were moved to much higher-achieving schools than the ones they left; FCAT math and reading scores were approximately half a standard deviation higher, on average, in

their new schools. Similarly, math and reading proficiency rates were much higher: 48 percent to 65 percent in math and 27 percent to 56 percent in reading. On Florida’s accountability grading system, teachers were moved, on average, from D schools (2.2) to B schools (4.0). Students in receiving schools were also absent substantially less often (11.8 to 7.8 times per year).

\section{Which Teachers Were Involuntarily Transferred and Who Replaced Them?}

Next, we ask which teachers in schools utilizing the involuntary transfer policy were chosen for transfer. Characteristics of transferred teachers, especially those related to job performance, are relevant to both our equity and efficiency examinations. In particular, if schools 
systematically identified less productive teachers for transfer, then moves from lower- to higherperforming schools are consistent with an equity improvement. The potential to increase teacher productivity is greater in moving low-performers as well.

Within transferring schools, we examine characteristics of the teacher's job, such as whether it was in a tested grade and subject, and teachers' observable qualifications, such as years of experience. We also examine two measures of teacher performance or productivity. One is teacher absences in the year prior to the transfer, which is the sum of sick leave, personal leave, and other absences, excluding absences for professional development. The other is teachers' value-added to student achievement gains in math and reading, which we can calculate for a subset of teachers in the analysis. The Appendix provides a description of how we created these value-added measures.

As with the schools analysis, we start by conducting $t$-tests that compare the characteristics of teachers who are involuntarily transferred, those who voluntarily transfer, and those who leave M-DCPS with teachers who stay at the school. We use staying teachers as the reference group because these are the teachers who could have been involuntarily transferred but were not. Teachers who moved on their own or left the district presumably did not need to be transferred involuntarily by the district to remove them from the school.

Table 4 presents comparisons. Most centrally, the comparisons show that involuntarily transferred teachers tended to be less productive than other teachers. They were absent more often than other teachers (10.7 days, on average, vs. approximately nine days for both the stayer and voluntary transfer groups). ${ }^{13}$ In math, involuntarily transferred teachers had statistically

\footnotetext{
${ }^{13}$ Absences for the "leavers" category are very low compared to the other groups. On average, however, teachers in the leavers category were only present for 35 percent of the days in the 180-day school year according to the data, so we assume they had fewer absences because they left early in the year.
} 
significantly lower value-added scores than stayers in the year of the transfer, based on a valueadded model that includes school fixed effects (i.e., estimates are within-school). They also had lower value-added scores in reading, though this difference is not statistically significant. Notably, involuntarily transferred teachers were much more likely than any of the other groups both to teach in a tested grade and subject combination in the transferring school and to have previously been moved from a tested classroom to a non-tested classroom. This latter difference may suggest that school leaders previously had attempted to act strategically in moving teachers away from subject and grade combinations important to school accountability before moving the teacher to another school altogether. ${ }^{14}$

Involuntary transfer teachers also differed from other teachers on other dimensions. They were more likely to be female and black than were teachers who stayed, voluntarily transferred, or left M-DCPS. While they were virtually identical to stayers in age and education level, involuntary transfers had about one less year in the current position. Moreover, the age experience, and job tenure profiles were more similar to stayers than to voluntary transfers; compared to voluntary transfers, involuntarily transferred teachers were approximately three years older, more experienced by two years, and had been in their current school approximately a year longer, on average. Differences with leavers are even more pronounced. The similarities of involuntary transfer teachers to stayers on these dimensions—and the dissimilarities with voluntary transfers and leavers—are consistent with the idea that principals targeted to teachers for transfer who they perceived to be unlikely to leave the school on their own.

We use multinomial logit models to predict the likelihood that a teacher within a school is involuntarily transferred, voluntarily transfers, or leaves M-DCPS relative to staying at his or

\footnotetext{
${ }^{14}$ As further evidence, we also found that while 35 percent of involuntarily transferred teachers were in tested subjects and grades prior to the move, after the transfer, this percentage had fallen to 30 percent.
} 
her school as a function of teacher and principal characteristics. These models help answer whether factors such as experience and performance are associated with being involuntarily transferred after controlling for other potentially contributing factors. Equation 2 describes these analyses:

$$
P_{t s y}(\text { teacher status }=m)=\frac{e^{f}}{1+\sum_{j=2}^{M} e^{f}}
$$

where

$$
f=\beta_{0}+T_{s y} \beta_{1}+P_{s y} \beta_{2}+\varepsilon_{s y}
$$

In Equation 2, teacher status can be defined as one of four categories, $m$ : (1) stays at school, (2) involuntarily transferred, (3) voluntarily transfers, and (4) leaves M-DCPS. The probability that teacher $t$ in school $s$ is in categories $1,2,3$, or 4 following year $y$ is a function of teacher characteristics $T_{s y}$, principal characteristics $P_{s y}$, and a random error term $\varepsilon_{s y}$. We cluster standard errors at the school level and include only schools involuntarily transferring at least one teacher. Table 5 presents the estimates of these models in terms of relative risk ratios, with "stayer" as the base group. Model 1 includes only teacher characteristics. Model 2 adds principal characteristics, while, given recent research demonstrating the importance of relational demography for teacher labor market decisions (e.g., Grissom \& Keiser, 2011), model 3 adds indicators for race and gender congruence between the teacher and principal.

All three models provide similar estimates of the relationship between teacher characteristics and the three types of job transition. Most central to our analysis is whether school leaders chose to transfer less productive teachers. The results suggest that the answer is a qualified yes. Involuntary transfers had significantly higher absences rates in the year prior to the transfer than did stayers. The relative risk ratio for value-added (math and reading averaged) is 
smaller than 1 but not statistically significant. ${ }^{15}$ Among teachers teaching in tested grades, the ones transferred did not have value-added scores that were statistically worse than those of who stayed. Although excluded for brevity, we also estimated models dropping value-added and including an indicator for teaching in a tested grade and subject and found this variable to be positively associated with being involuntarily transferred (odds ratio $=1.58, p<0.01) .{ }^{16}$

The table also shows that the probability of being involuntarily transferred increased with experience, a result that is consistent both with the hypothesis that principals used the policy to remove teachers who would be less likely to leave on their own and with the possibility that principals were less likely to move early-career teachers because they have less information about their performance and match with the school. Race was also a predictor of involuntary transfer. Even conditioning on performance measures, black teachers were more likely to be involuntarily transferred.

While no principal characteristics were statistically significant predictors of involuntary turnover probability on their own (model 2), when we add indicators for whether the gender and race/ethnicity of the teacher and principal match, however, we do find some evidence that this match matters (model 3). Principals were less likely to involuntarily transfer teachers of the same racial or ethnic background and also of the same gender. These results are consistent with other evidence suggesting that congruence among teachers and their principals influences teacher labor market outcomes, perhaps because principals and teachers from the same demographic

\footnotetext{
${ }^{15}$ We also ran models including only math value added or only reading value added. For math only, the value-added coefficient was negative (i.e., relative risk ratio below 1 ) and statistically significant at the 0.10 level in some models for involuntary transfer. For reading the coefficients were always negative but never statistically significant. We also estimated models using the average of all previous years of value-added that could be calculated and did not find qualitatively different results.

${ }^{16}$ This variable was also negatively associated with leaving (odds ratio $=0.43, p<0.01$ ) but not statistically associated with voluntarily transferring.
} 
backgrounds tend to view one another more positively (Grissom \& Keiser, 2011; Grissom, Nicholson-Crotty, \& Keiser, 2012; Jacob, 2011). ${ }^{17}$

The gains for schools involuntarily transferring teachers depends not only on whom they transfer but also on the teachers that replace transferred teachers. Replacing relatively ineffective teachers with similarly ineffective teachers will have no impact on performance in the schools utilizing the policy, and in fact, if the replacements are substantially lower performing, any gains from moving teachers could be completely offset. Unfortunately, making direct comparisons between exiting and entering teachers is difficult because of the restructuring of staff positions that occurred at some schools, but we attempt to assess the characteristics of transferred teachers relative to their replacements, first by comparing them to their direct subject-grade replacements if we could identify them (this could be done for approximately 30 percent of transferred teachers), and then by comparing them to all new hires in the school the following year.

Table 6 shows the results of $t$-tests comparing the characteristics of replacements and new hires in year $t$ with the characteristics of the involuntary transfers in year $t-1 .{ }^{18}$ We find that, compared to the involuntarily transferred teachers, replacements and new hires were younger and had significantly fewer years of experience within M-DCPS. While involuntarily transferred teachers were absent 11 days, on average, in the year before they were transferred, the replacement teachers and new hires, were absent only an average of 9 days $(p<0.01$ for both differences). When possible, we also compared value-added in both math and reading among the three groups. The sample sizes for these comparisons are significantly smaller because value-

\footnotetext{
${ }^{17}$ For example, Grissom and Keiser (2011) find that teachers with own-race principals are less likely to turn over, which they attribute to differences in the distribution of organizational benefits (e.g., job recognition) perceived by those teachers and in opportunities to earn supplemental pay.

${ }^{18}$ The figures for the involuntary transfers differ somewhat from those shown in Table 1 because they are calculated only for the first two transfer cohorts (2009 and 2010). At the time of this analysis, data from 2012 were not yet available, so we could not identify replacements and new hires for the 2011 cohort.
} 
added can only be estimated for teachers with teaching experience in tested grades and subjects; this information is not available for the large fraction of replacements and new hires who are beginning teachers or for those whose previous teaching was outside tested classrooms. Still, the patterns are consistent with the conclusion that replacement teachers were higher performers than the involuntarily transferred teachers. Comparing direct replacements to transfers shows differences of +0.06 s.d. in math and 0.46 s.d. in reading, though only the latter difference is statistically significant $(p<0.05)$. For all new hires, a larger group, the differences are +0.09 s.d. in math and 0.40 s.d. in reading, with the reading difference statistically significant at the 0.05 level. Overall, these results suggest that the involuntarily transferred teachers were replaced by more productive teachers when they were moved out of their schools.

\section{Did Involuntary Transfers Affect Teacher Productivity?}

Our final goal is to understand whether the productivity of involuntarily transferred teachers changed as a result of the policy. We assess this by comparing teachers' absences and contributions to student test score growth before and after transferring.

\section{Teacher Absences}

Although not a direct measure of a teacher's impact on the school, teacher absences are a key component of job performance. Research shows that student performance declines as teacher absences increase (Herrmann \& Rockoff, 2012). High teacher absence rates are also linked to more negative school climates, which may in turn hurt school outcomes (Norton, 1998). A change in teacher absences before and after an involuntary transfer thus provides evidence that 
the policy impacted a relevant teacher performance indicator. We estimate the effect of the policy teacher absences using the following model:

$$
Y_{t s y}=\beta_{0}+\left(I T_{t y}\right) \beta_{1}+(I T \times P)_{t y} \beta_{2}+T_{t s y} \beta_{3}+S_{s y} \beta_{4}+\delta_{y}+\varepsilon_{t s y}
$$

Equation 3 models teacher $t$ 's absences $Y$ in school $s$ in year $y$ as a function of ever being involuntarily transferred $(I T)$ and an interaction with the post-transfer period $(I T \times P)$. The main coefficient of interest is $\beta_{2}$. The model includes controls for teacher $(T)$ and school $(S)$ characteristics, plus year fixed effects $\left(\delta_{y}\right)$ and a random error term $\left(\varepsilon_{t s y}\right)$. In some models we also include school or teacher fixed effects. Models are estimated via OLS, clustering standard errors at the teacher level. ${ }^{19}$

Results are shown in Table 7. Even-numbered columns include school fixed effects (and drop school characteristics). Columns 5 and 6 include teacher fixed effects (and drop teacher characteristics). The different specifications provide very consistent results. On average, teachers who were involuntarily transferred were absent between 1.6 and 2 days more often than similar teachers in similar (or identical) school environments. This average is offset, however, in the post-transfer period, with the coefficients suggesting that involuntarily transferred teachers were absent between 1.2 and 1.6 days less often after being moved. ${ }^{20}$ These coefficients are significant at the 0.01 level in all models. The average absence rate among teachers in sending schools was 8.5 days, so a reduction of this size is practically significant as well. This table provides evidence that the transfer policy identified less productive teachers (i.e., those with higher absence rates)

\footnotetext{
${ }^{19}$ Given the count nature of the absences variable, we also estimated these models using negative binomial regression. The marginal effects were virtually identical to the OLS results, perhaps because the distribution of absences is not as skewed as we might predict (mean $=9.6$; median $=10$ ).

${ }^{20}$ Removing controls from the analyses did not change the teacher absence patterns we observed. In other words, teachers were absent less after the involuntary transfer in absolute terms, not only in comparison to teachers in similar positions.
} 
for transfer and that these teachers responded to the transfer by being absent less often, suggesting the policy resulted in higher productivity for these teachers on this measure. ${ }^{21}$

\section{Student Achievement}

Contributions to student achievement gains are a more explicit measure of teachers’ job performance. Unfortunately, measuring changes in teachers' contribution to student achievement is difficult when a teacher changes schools, particularly when that teacher moves to meaningfully different types of schools as they did under the involuntary transfer policy. The difficulty comes from the need to separate the effect of the teacher from the effects of student background characteristics and the effects of the school from the effects of the teacher. When the teacher remains in the same school then these contextual factors stay relatively constant; when the teacher changes schools, they do not. Thus, if a teacher's students learn relatively more when the teacher is in one school we cannot know for sure whether that is because the teacher did a better job or because the students would have learned more anyway. We can think of this as a problem of the shifting comparison group. It is potentially important to include a school fixed effect to control for school context and compare teachers only to other teachers in the same environment. But the involuntary transfer policy moved teachers to higher-performing schools, meaning the comparison group of teachers post-transfer in the school fixed effects models is likely to be a more productive group, as measured by test scores. So, even if we see that, post-transfer, the involuntarily transferred teachers performed worse than the average teacher in their school, the fact that they are worse among a higher-performing group makes coming to conclusions about whether the policy affected their performance in absolute terms a challenge. There is no clear

\footnotetext{
${ }^{21}$ In Appendix Table 2, we compared absences in receiving schools between involuntarily transferred teachers and average new hires in those schools but did not find that they were different.
} 
way around this challenge, but we use a number of approaches to provide insight into potential changes in productivity.

We model changes in teacher effectiveness in a number of ways. The baseline specification for these models is shown in Equation 4.

$A_{i t s y}=\beta_{0}+A_{i t s(y-n)} \beta_{1}+X_{i t s y} \beta_{2}+\left(I T_{t y}\right) \beta_{3}+(I T \times P)_{t y} \beta_{4}+C_{t s y} \beta_{5}+S_{s y} \beta_{6}+E_{t y} \beta_{7}+\delta_{y}+\varepsilon_{i t s y}$

We predict achievement for student $i$ with teacher $t$ in school $s$ in year $y$ as a function of $n$ achievement lags $A_{i t s(y-n)}$, extensive time-varying student characteristics $X_{i t s y}$, an indicator of whether the teacher has ever been involuntarily transferred $I T_{t y}$, and the interaction of ever having been involuntarily transferred and post-transfer indicators $I T \times P_{t y}$, classroom characteristics $C_{t s y}$, time-varying school characteristics $S_{s y}$, teacher experience indicators $E_{t y}$, school year indicator variables $\delta_{y}$, and a random error term $\varepsilon_{s y}$. A list of control variables is provided at the bottom of Table 7. We are primarily interested in $\beta_{2}$ and $\beta_{3}$, which show involuntarily transferred teachers' effectiveness before and after the transfer. For a more complete set of comparisons, we estimate Equation 3 with different combinations of school and teacher fixed effects. We present models that include two years of lagged achievement scores, though our results are qualitatively similar if we use one lag instead. In some models we also include indicators for whether the teacher ever transferred voluntarily, plus the interaction between the voluntary transfer and the time period after the transfer, to further differentiate the effect of the involuntary transfer from the effect of moving in general. We estimate Equation 3 separately for math and reading using data from the 2005-06 through 2010-11 school years. In all of these models, we cluster standard errors at the teacher-year level. 
Table 8 provides the results. For brevity, we omit coefficients from the control variables from the table. ${ }^{22}$ Columns 1 through 4 show the results for math and Columns 5 through 8 show the results for reading. The first two columns for each outcome contain school fixed effects while the second two contain teacher fixed effects. The first coefficient in column 1 shows that, conditional on other characteristics, students in classrooms of involuntarily transferred teachers performed worse on average than other students in the same schools $(\beta=-0.02)$. The second coefficient shows that the new students of involuntarily transferred teachers performed even worse relative to the average student in their schools after the transfer $(\beta=-0.07) .{ }^{23}$ Both are statistically significant at the 0.05 level. For comparison, the size of this coefficient is approximately the same as the conditional difference in math performance associated with being an African American student in this sample, relative to white students. ${ }^{24}$ Column 2 adds indicator variables for whether the teacher ever transferred (voluntarily) and an interaction between that variable and the post-transfer period, which lets us rule out the possibility that the coefficients are picking up an effect common to all transfers. ${ }^{25}$ The inclusion of these variables leaves the point estimates for the two involuntary transfer variables unaffected. These results provide evidence that involuntarily transferred teachers were less effective relative to the other teachers in their school prior to transfer and were even less effective relative to the teachers in their new

\footnotetext{
${ }^{22}$ The control variables generally behave as expected. Lagged test scores at the student, classroom, and school level are highly predictive of current test scores in both subjects. Among other student-level characteristics, lagged absences predict lower current test score performance in all models, as do lagged suspensions, free/reduced lunch status, and being black or Hispanic. Female students, on average, are lower performing in math but not reading. ${ }^{23}$ We also estimated models without school fixed effects. For math, these models yield a somewhat larger coefficient on the post-transfer interaction term for involuntarily transferred teachers $(\beta=-0.10, p<0.01)$. For reading, the coefficient from a model without school fixed effects is approximately the same as the one shown in Column 5 and not statistically significant.

${ }^{24}$ The coefficient on African American student is $-0.08, p<0.01$.

${ }^{25}$ If a teacher transferred more than once, the post-transfer indicator is set equal to 1 in any period after the first transfer.
} 
school after the transfer. This change could be due to a drop in productivity for the transferring teacher or to having a stronger set of comparison teachers after transferring.

Columns 3 and 4 add teacher fixed effects, first without then with school fixed effects. ${ }^{26}$ Including a teacher fixed effect creates a comparison of how much students learn relative to similar students when they were taught by this teacher before the transfer and when they were taught by this teacher after the transfer. Adding the school fixed effect into this equation removes the effect of the specific school that the teacher taught in each year. Column 3 estimates a withinteacher change in student test score growth of $-0.12(p<0.01)$. The estimate in column 4 , which includes both school and teachers fixed effects, shows an effect approximately the same as the one estimated without the teacher effect $(\beta=-0.06, p<0.01)$. This coefficient is educationally significant, equaling just over twice the conditional male-female gap in math performance in this sample. ${ }^{27}$ Again, these results provide some evidence that productivity dropped after transfer, even for these less effective teachers, though we cannot rule out the possibility that this drop is due to an increase in the productivity of the teachers to which we are comparing them.

The results for reading in Columns 5-8 show little evidence of productivity differences for involuntarily transferred teachers post-transfer. The pre-transfer coefficients show that these teachers were less effective than their peers with observationally similar students prior to transfer, but the post-transfer results show no statistically significant gain or loss.

A drawback of the analysis presented in Table 8 is that models that include school fixed effects compare the involuntarily transferred teacher to the average teacher in sending and receiving schools. A consequence of the policy for receiving schools is that it fills an open

\footnotetext{
${ }^{26}$ Models including both school and teacher fixed effects are estimated using the FELSDVREG routine in Stata (Cornelissen, 2008).

${ }^{27}$ The coefficient on Female student is $-0.026, p<0.01$.
} 
teaching slot with a transferred teacher, so from the receiving school's perspective, the appropriate comparison might be the average potential teacher the school could have hired, rather than the average teacher overall, which may be quite different. While we cannot observe potential replacements directly, we provide evidence on this point by estimating a version of Equation 3 with school fixed effects that limits the sample to teachers in all sending and receiving schools. We then include an indicator variable identifying any teacher hired into the school, plus interactions between this variable and involuntary transfer $x$ pre-transfer and involuntary transfer $x$ post-transfer, with the latter estimating the difference in productivity between an involuntarily transferred teacher and the average replacement at receiving schools.

The results of this analysis, provided in Table 9, provide evidence that involuntarily transferred teachers perform substantially lower than potential replacements in both math and reading. Post-transfer, the difference between an involuntarily transferred teacher and the average new hire at schools receiving those transfers is approximately -0.08 s.d. in math $(p<$ $0.01)$ and -0.02 s.d. in reading $(p<0.10)$, controlling for other factors. Thus, while the test score analysis does not allow us to conclude conclusively that the performance of involuntary transfers worsened after transferring, we do have evidence that they performed worse than other teachers that the school would likely have been able to hire. ${ }^{28}$

Another drawback to the student achievement gains analysis is that gains can only be analyzed for teachers assigned to tested grades and subjects before and after a transfer. If a transferred teacher is relatively low-performing in teaching core subjects, the receiving principal may wish to place the teacher in an untested grade or subject to minimize the impact of that teacher on its own standardized test score performance. To test for evidence of such strategic

\footnotetext{
${ }^{28}$ We find no evidence in Table 9 of a difference in work absences between involuntarily transferred teachers posttransfer and potential replacements.
} 
behavior, we estimated logit models predicting the probability of teaching an untested grade or subject as a function of teacher characteristics, school characteristics or a school fixed effect, an indicator for being an involuntarily transferred teacher, and an interaction with the post-transfer period. We estimated models over the full teacher sample for 2007-08 to 2010-11. Table 10 gives the results.

Conditional on other observable characteristics, involuntarily transferred teachers were somewhat less likely to be in untested grade/subject combinations prior to the transfer. After the transfer, however, they were significantly more likely to be placed in untested grades. In column 2, which includes a school fixed effect, the odds ratio on the interaction term is $2.2(p<0.01)$, meaning that the odds of being in an untested grade or subject were about twice as large for involuntarily transferred teachers than for other teachers in their schools. This finding highlights the importance of interpreting the student test score gains results in Table 8 as being conditional on remaining in a tested grade and subject.

\section{DISCUSSION AND CONCLUSIONS}

Can involuntary teacher transfer policies be used to improve equity and efficiency in urban schools? Evidence from the implementation of such a policy in Miami-Dade County Public Schools suggests that they can, though the benefits are likely to come more from equity improvements than from efficiency improvements. Our analysis shows that M-DCPS used the policy to target relatively less productive teachers in its lowest-performing schools, particularly those who may have been less likely to voluntarily leave the school. These teachers were less effective in math and reading and more likely to be absent from work than other teachers in the same schools. When these teachers were moved, they were sent to positions in higher- 
performing schools with fewer disadvantaged students; there is little evidence that the policy resulted in a "dance of the lemons." We also find evidence that, in replacing these teachers, sending schools were able to bring in teachers who achieved higher student test scoresparticularly in reading — and were absent from work less often. Taken together, this evidence suggests that the involuntary transfer policy as implemented in M-DCPS enhanced equity across schools by increasing the quality of the teaching resources directed towards the students who needed them most.

The implications of the policy for district efficiency are less straightforward but suggest some potential gains as well. Given the low costs of implementing the policy, the question for efficiency is whether the policy increased overall district performance. On one hand, consistent with the claim that the policy improved efficiency, our results show that involuntarily transferred teachers' absenteeism rates declined significantly in their new schools. Their replacements in their old schools also had fewer absences. Considering research that shows that student learning increases when teachers miss work less often (Miller, Murnane, \& Willett, 2008), these results push the scales toward a net improvement in teacher productivity. On the other hand, our analysis of transferred teachers' test score gains prior to and after the involuntary transfer does not indicate that the district achieved higher performance from its existing teachers by improving the match between teachers and their schools through the transfers. Transferred teachers performed relatively poorly, especially in terms of value added to students' math achievement, in both their old and new schools. Whether they are more or less effective after transfer is difficult to assess because the group of teachers against whom the transferring teacher is compared in computing value-added (i.e., teachers teaching similar students in similar schools) changed as a 
result of the transfer. We do find suggestive evidence that involuntarily transferred teachers took slots in their new schools that would have gone to higher-performing new hires.

A number of factors complicate our attempt to pin down the overall impact on efficiency. First, the recency of the transfer policy implementation gives us only a few years with which to estimate post-transfer effects. We cannot yet assess whether transferred teachers improved in their new school over time. Second, we find that transferred teachers tended to be placed in untested grades or subjects after the transfer. Because we cannot calculate value-added for teachers whose students are not tested, we cannot use test scores to examine productivity for those teachers. Their exclusion from the test score analysis may bias in those results, particularly if receiving principals put teachers they anticipated to be especially low performers in classrooms not assessed for school accountability purposes.

A third complication arises from the finding that the policy moved teachers from schools with large populations of disadvantaged, low-achieving students to schools with many fewer such students. Given correlations observed in other research between student achievement and demographics and other working conditions variables (e.g., Grissom, 2011; Ladd, 2011; Loeb, Darling-Hammond, \& Luczak, 2005), involuntarily transferred teachers likely were better off with respect to working conditions post-transfer. Unless these gains are offset by unobservable losses, such as stigma from being identified as a low-performing teacher, these more positive working conditions may lead to greater job attachment and lower probability of turnover. Although the short time elapsed since the implementation of the policy gives us limited years in which to examine attrition, logit models of the probability of exit indeed suggest that, conditional on teacher and school characteristics, involuntarily transferred teachers from the first two years of the policy's use were significantly less likely to leave the district in the one or two subsequent 
years than other M-DCPS teachers (see Appendix Table A1). ${ }^{29}$ The possibility that the policy increased the propensity of apparently lower-performing teachers to stay in the district by transferring them to schools with more positive working conditions works against an efficiency improvement.

Even given the mixed results on efficiency gains, our findings suggest that an involuntary transfer policy can be employed to promote school district goals and benefit students. Consistent with other studies finding that more restrictive transfer provisions in district-teacher contracts are associated with more unequal distributions of teacher qualifications across schools (Moe, 2005), our results demonstrate that district-initiated teacher transfers can be used strategically to "undo" the well-documented systematic sorting of less qualified teachers into the neediest schools (e.g., Lankford, Loeb, \& Wyckoff, 2002). They can also, along some dimensions (e.g., attendance), boost the productivity of relatively low-performing teachers. Of course, the operative word in both of the preceding sentences is can. Our data came from just one urban district with a particular plan for identifying teachers for transfer and moving them to new schools. Design and implementation choices are important, and we cannot know for sure how different choices or different political or organizational contexts would lead to different results. As an example, MDCPS utilized the policy in fewer than 10 percent of its schools. An implementation plan with more widespread usage may not have had the same effects.

Given the importance of implementation, we may question the degree to which these results speak to the typical case of involuntary transfers necessitated by reductions-in-force

\footnotetext{
${ }^{29}$ The odds ratio on involuntary transfer teacher in a model predicting the probability of exit from district as a function of teacher and school characteristics, estimated over all available years since the first year of transfers, is $0.35(p<0.01)$. Conditional logit models with fixed effects for schools yielded very similar results. We also tested whether this association is moderated by teacher value-added in math and reading but found no evidence of an interaction.
} 
(RIFs). This question is important in light of the recent economic downturn, which has necessitated the elimination of teaching positions in many districts nationwide (see, for example, Chen and Hernandez (2011) on the loss of teaching positions due to budget constraints in New York City). A primary contrast between the M-DCPS case and involuntary transfers compelled by RIFs is that the latter often are governed by seniority provisions in CBAs or other district policies, leaving little room for them to be implemented strategically. Our results demonstrate that strategic involuntary transfers like the ones in M-DCPS present an opportunity to pursue broader district goals, such as equity, and suggest that districts may benefit from negotiating different terms for RIF-induced transfers that allow teacher performance to be taken into account. This conclusion is consistent with earlier work that has estimated the potential benefits of strategic dismissals in the face of RIFs in contrast to last-in-first-out approaches (Boyd, Lankford, Loeb, \& Wyckoff, 2011; Goldhaber \& Theobald, 2011)

Our results are also consistent with other work demonstrating that school principals can, when given the opportunity, successfully identify less productive teachers for staffing actions. Like Jacob’s (2011) study of teacher dismissals in Chicago, we find that principals are more likely to act to move teachers out of their schools who have lower value-added scores and who are absent from work more often. Also like that study, we find evidence that principals are less likely to identify teachers with whom they share demographic characteristics, though we differ in finding little evidence of a relationship between principal experience and the likelihood the policy was used. These findings suggest the need for additional research into the complexities of how principals make human resource decisions in their schools.

The study faces several limitations in addition to the concern about generalizability. First, we analyze the effects of the M-DCPS transfer policy over a relatively short time frame. A 
longer term study utilizing more data might obtain more precise or more nuanced results.

Second, we are limited in our analyses to administrative data. We would especially benefit from process data collected from schools to help us understand how principals went about identifying some teachers over others and, in receiving schools, whether principals approached working with transferred teachers differently. Third, we are able to examine only a subset of the ways in which utilization of the involuntary transfer policy affected efficiency and equity in the district. For example, it may be that the threat of being involuntarily transferred affects the productivity of teachers in a school—either positively or negatively—beyond those chosen for transfer. Relatedly, while the results here suggest productivity gains in transferring schools, the relatively small number of schools using the involuntary transfer policy over the time period we study gives us too little power to test for overall improvements in student test scores from the implementation of the policy.

Future work might address these limitations by identifying other school districts making use of strategic involuntary transfers to assess whether the patterns we have described are characteristics of district implementation of such policies more broadly. Researchers might also examine the impact of involuntary transfer policies on other organizational outcomes, such as parent satisfaction or teacher morale, for which such policies may have unintended consequences. At a more basic level, research digging into the specific terms of written involuntary transfer policies enshrined in CBAs and elsewhere to elucidate the degree to which districts have the statutory capacity to behave strategically in this area would be useful. It would also provide a jumping-off point for investigating the organizational and contextual constraints that apparently lead districts to make use of such strategy sparingly. 


\section{Appendix: Estimating Teacher Value-Added}

Equation A1 describes our teacher value-added model, which predicts the achievement gain between year $t-1$ and year $t$ for student $i$ with teacher $j$ in school $s$ as a function of timevarying student characteristics $\left(X_{i j s t}\right)$, classroom characteristics $\left(C_{j t}\right)$, time-varying school characteristics, $\left(S_{s t}\right)$, student fixed effects $\left(\pi_{i}\right)$, and a teacher-by-year fixed effect $\left(\delta_{j t}\right)$.

$$
A_{i j s t}-A_{i j s(t-1)}=\beta X_{i j s t}+\eta C_{j t}+\gamma S_{s t}+\pi_{i}+\delta_{j t}+\varepsilon_{i j s t}
$$

The parameter $\delta$ reflects the contribution of a given teacher to growth in student achievement each year, after controlling for all observed time-varying student and school characteristics, observed and unobserved time-invariant student characteristics, and characteristics of students' classrooms that may be associated with learning. It shows whether the achievement gain for a given student is higher or lower the year they have a particular teacher relative to their average gains from years they are in classes with other teachers.

The test scores used to generate the value-added estimates are the scaled scores from the FCAT, standardized to have a mean of zero and a standard deviation of one for each grade in each year. Subscripts for subjects are omitted for simplicity, but we estimate Equation A1 separately for student achievement gains in math and reading. Gains in math and reading are attributed to teachers of self-contained elementary school classrooms for students in grades 5 and below. For older students (who have multiple teachers), gains in math and reading are attributed to math and English teachers. These teachers are identified from student course records, which list the course title and instructor for each of a student's courses in each year. Since we have eight years of test data (i.e., 2003 through 2011) and students are tested in a wide range of grades (3-10), we observe over half of tested students in two or more schools. 
After estimating Equation A1, we save the teacher by year fixed effects and their corresponding standard errors. The estimated coefficients for these fixed effects include measurement error as well as real differences in achievement gains associated with teachers. We therefore shrink the estimates using the empirical Bayes method to adjust for sampling error and bring imprecise estimates closer to the mean (see Loeb, Beteille, \& Kalogrides (2012) for a description of the shrinking). After shrinking the value-added estimates, we standardize them to have a mean of zero and a standard deviation of one in each year to facilitate interpretation. 


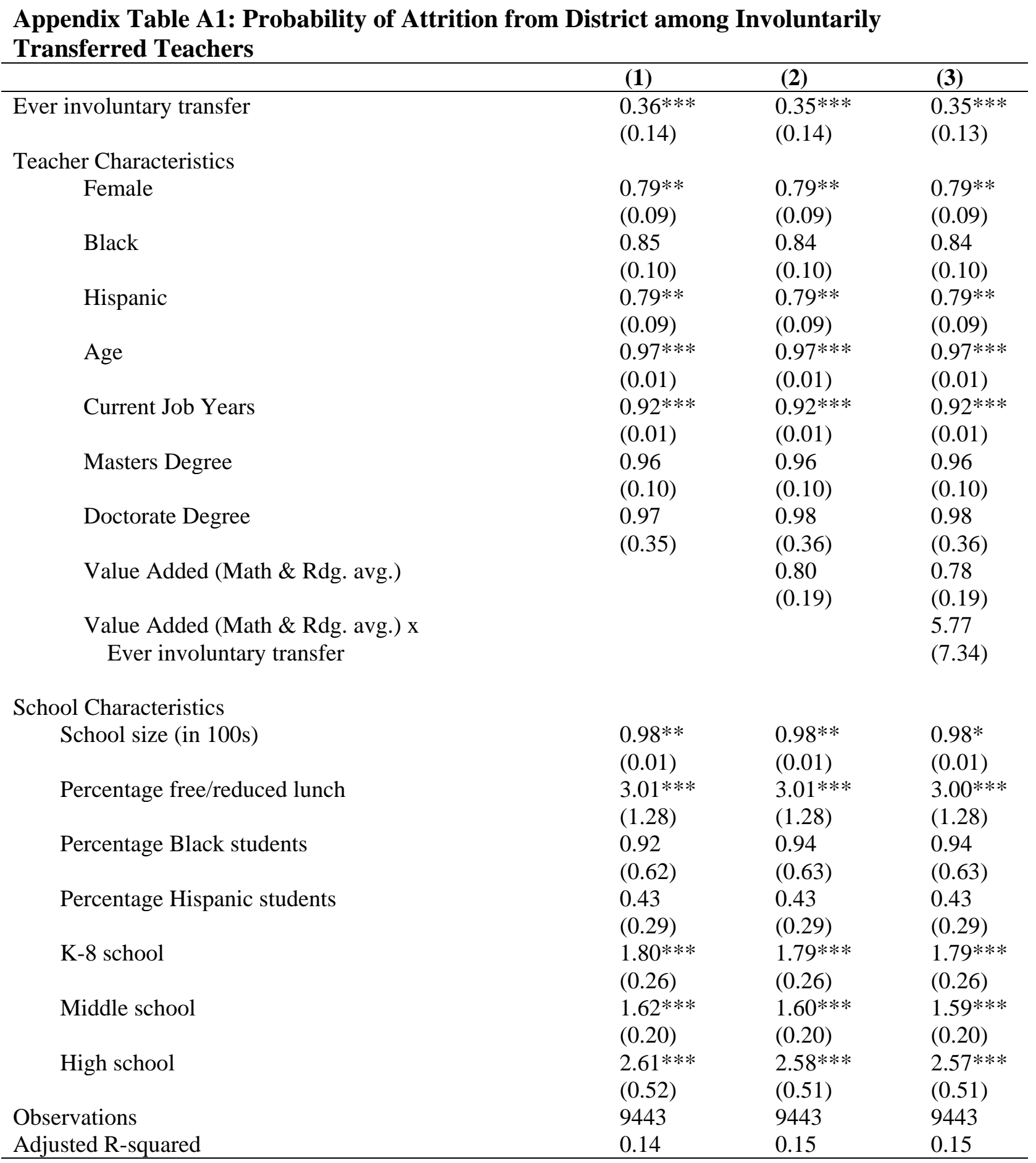

Note: The table shows estimates from a logit model predicting the probability that a M-DCPS teacher in any school during the first 2 years of involuntary transfers exited the district in a subsequent year (data availability prevents including the third year of the policy). Coefficients presented as odds ratios.

Standard errors in parentheses, clustered at teacher level. ${ }^{*} \mathrm{p}<.10,{ }^{* *} \mathrm{p}<.05,{ }^{* * *} \mathrm{p}<.01$. All models also include teacher experience indicators. 


\section{REFERENCES}

Boyd, D., Lankford, H., Loeb, S., \& Wyckoff, J. (2005). Explaining the short careers of highachieving teachers in schools with low-performing students. American Economic Review, 95, 166-171.

Boyd, D., Lankford, H., Loeb, S., \& Wyckoff, J. (2011). Teacher layoffs: An empirical illustration of seniority v. measures of effectiveness. Education Finance and Policy, 6(3), 439-454.

Chen, D.W., \& Hernandez, J.C. (2011, May 6). Mayor announces plan to lay off thousands of teachers. The New York Times. Retrieved from http://www.nytimes.com/2011/05/06/nyregion/bloomberg-budget-will-seek-400-millionmore-in-cuts.html? $\mathrm{r}=1$.

Cohen-Vogel, L., \& Osborne-Lampkin, L. (2007). Allocating quality: Collective bargaining agreements and administrative discretion over teacher assignment. Educational Administration Quarterly, 43, 433-461.

Cornelissen, T. (2008). The Stata command felsdvreg to fit a linear model with two highdimensional fixed effects. Stata Journal 8, 170-189.

Goldhaber, D. \& Theobald, R. (2011). Managing the teacher workforce in austere times: The implications of teacher layoffs. CEDR Working Paper 2011-1.3. University of Washington.

Grissom, J.A. (2011). Can good principals keep teachers in disadvantaged schools? Linking principal effectiveness to teacher satisfaction and turnover in hard-to-staff environments. Teachers College Record, 113, 2552-2585.

Grissom, J.A., \& Keiser, L. (2011). A supervisor like me: Race, representation, and the satisfaction and turnover decisions of public sector employees. Journal of Policy Analysis and Management, 30, 557-580.

Grissom, J.A., Nicholson-Crotty, J., and Keiser, L. (2012). Does my boss’s gender matter? Explaining job satisfaction and employee turnover in the public sector. Journal of Public Administration Research and Theory, 22, 649-673.

Guarino, C., Santibañez, L., \& Daley, G. (2006). Teacher recruitment and retention: A review of the recent empirical literature. Review of Educational Research, 36, 63-87.

Herrmann, M. A., \& Rockoff, J. E. (2012). Worker absence and productivity: Evidence from teaching. Journal of Labor Economics, 30(4), 749-782.

Jackson, C.K., \& Bruegmann E. (2009). Teaching students and teaching each other: The importance of peer learning for teachers. American Economic Journal: Applied Economics, 1, 85-108. 
Jackson, C.K. (2010). Match quality, worker productivity, and worker mobility: Direct evidence from teachers. National Bureau of Economic Research Working Paper No. 15990.

Jacob, B. A. (2011). Do principals fire the worst teachers? Educational Evaluation and Policy Analysis, 33(4), 403-434.

Koski, W.S., \& Horng, E.L. (2007). Facilitating the teacher quality gap? Collective bargaining agreements, teacher hiring and transfer rules, and teacher assignment among schools in California. Education Finance and Policy, 2, 262-300.

Keigher, A. (2010). Teacher attrition and mobility: Results from the 2008-09 Teacher Follow-up Survey (NCES 2010-353). U.S. Department of Education. Washington, DC: National Center for Education Statistics. Retrieved from http://nces.ed.gov/pubsearch.

Ladd, H.F. (2011). Teachers' perceptions of their working conditions: How predictive of planned and actual teacher movement? Educational Evaluation and Policy Analysis, 33, 235-261.

Lankford, H., Loeb, S., \& Wyckoff, J. (2002). Teacher sorting and the plight of urban schools: A descriptive analysis. Educational Evaluation and Policy Analysis, 24, 37-62.

Levin, J., Mulhern, J., \& Schunck, J. (2005). Unintended consequences: The case for reforming the staffing rules in urban teachers union contracts. Brooklyn, NY: The New Teacher Project.

Loeb, S., Darling-Hammond, L., \& Luczak, J. (2005). How teaching conditions predict teacher turnover in California schools. Peabody Journal of Education, 80, 44-70.

Loeb, S., Beteille, T., \& Kalogrides, D. (2012). Effective schools: Teacher hiring, assignment, development, and retention. Education Finance and Policy, 7(3), 269-304.

M-DCPS/UTD Successor Contract, 2006. Amended 2009. Retrieved November 1, 2012 from http://www2.dadeschools.net/employees/labor_union/UTD/index.htm.

Miller, R.T., Murnane, R.J., \& Willett, J.B. (2008). Do teacher absences impact student achievement? Longitudinal evidence from one urban school district. Educational Evaluation and Policy Analysis, 30, 181-200.

Moe, T.M. (2005). Bottom-up structure: Collective bargaining, transfer rights, and the education of disadvantaged children. Unpublished paper, Stanford University.

Moe, T.M. (2009). Collective bargaining and the performance of the public schools. American Journal of Political Science, 53, 156-174.

National Council on Teacher Quality. (2009). Teacher rules, roles, and rights: Miami-Dade County School District, Florida. Retrieved February 17, 2013 from http://www.nctq.org/tr3/districtHomepage.jsp?districtId=5. 
National Council on Teacher Quality. (2010). Bumping HR: Giving principals more say over staffing. Retrieved February 17, 2013 from http://www.nctq.org/tr3/docs/nctq_site_based_hiring.pdf.

Norton, M. S. (1998). Teacher absenteeism: A growing dilemma in education. Contemporary Education, 69(2), 95-99.

Strunk, K.O., \& Grissom, J.A. (2010). Do strong unions shape district policies? Collective bargaining, teacher contract restrictiveness, and the political power of teachers' unions. Educational Evaluation and Policy Analysis, 32, 389-406. 
Table 1: Descriptive Statistics for M-DCPS Schools and Personnel

\begin{tabular}{|c|c|c|c|c|c|}
\hline \multirow[b]{2}{*}{ Variable } & \multicolumn{3}{|c|}{ Entire District } & \multirow{2}{*}{$\begin{array}{c}\text { Schools with No } \\
\text { Involuntary } \\
\text { Transfers }\end{array}$} & \multirow{2}{*}{$\begin{array}{c}\text { Schools with } \\
\text { Involuntary } \\
\text { Transfers }\end{array}$} \\
\hline & $\mathrm{N}$ & Mean & SD & & \\
\hline \multicolumn{6}{|l|}{ School characteristics } \\
\hline Proportion female students & 1098 & 0.49 & 0.06 & 0.49 & 0.48 \\
\hline Proportion Black students & 1098 & 0.31 & 0.34 & 0.28 & $0.72 * * *$ \\
\hline Proportion Hispanic students & 1098 & 0.60 & 0.32 & 0.62 & $0.26 * * *$ \\
\hline $\begin{array}{l}\text { Proportion subsidized lunch eligible } \\
\text { Proportion limited English }\end{array}$ & 1098 & 0.72 & 0.23 & 0.71 & $0.83^{* * *}$ \\
\hline proficiency & 1098 & 0.19 & 0.15 & 0.2 & $0.11^{* * *}$ \\
\hline School size (in 100s) & 1098 & 8.12 & 5.34 & 7.87 & $11.63^{* * *}$ \\
\hline Proportion elementary school & 1098 & 0.54 & & 0.56 & $0.19 * * *$ \\
\hline Proportion K-8 school & 1098 & 0.14 & & 0.15 & 0.11 \\
\hline Proportion middle school & 1098 & 0.21 & & 0.21 & 0.25 \\
\hline Proportion high school & 1098 & 0.09 & & 0.07 & $0.45 * * *$ \\
\hline Standardized math score & 1098 & -0.04 & 0.38 & 0.00 & $-0.51 * * *$ \\
\hline Standardized reading score & 1098 & -0.04 & 0.39 & -0.01 & $-0.56 * * *$ \\
\hline Proportion proficient in math & 1098 & 0.64 & 0.16 & 0.65 & $0.48 * * *$ \\
\hline Proportion proficient in reading & 1098 & 0.59 & 0.18 & 0.61 & $0.27 * * *$ \\
\hline School accountability grade & 1098 & 4.11 & 1.15 & 4.25 & $2.22 * * *$ \\
\hline Student absences & 1098 & 7.70 & 2.53 & 7.41 & $11.78 * * *$ \\
\hline \multicolumn{6}{|l|}{ Principal characteristics } \\
\hline Female & 1098 & 0.69 & & 0.71 & $0.49 * * *$ \\
\hline Black & 1098 & 0.31 & & 0.29 & $0.52 * * *$ \\
\hline Hispanic & 1098 & 0.45 & & 0.47 & $0.27 * * *$ \\
\hline Age & 1098 & 50.23 & 7.92 & 50.45 & $47.43^{* * *}$ \\
\hline Experience (in years) & 1098 & 21.51 & 7.53 & 21.68 & $19.25 * * *$ \\
\hline Current position years & 1098 & 4.15 & 3.75 & 4.33 & $1.89 * * *$ \\
\hline Masters degree & 1098 & 0.64 & & 0.65 & $0.52^{* *}$ \\
\hline Doctorate degree & 1098 & 0.21 & & 0.21 & 0.25 \\
\hline \multicolumn{6}{|l|}{ Teacher characteristics } \\
\hline Female & 58702 & 0.77 & & 0.78 & $0.64 * * *$ \\
\hline Black & 57110 & 0.27 & & 0.24 & $0.53^{* * *}$ \\
\hline Hispanic & 57110 & 0.42 & & 0.44 & $0.17 * * *$ \\
\hline Age & 58702 & 44.67 & 11.65 & 44.74 & $43.89 * * *$ \\
\hline Experience (in years) & 58702 & 10.44 & 8.87 & 10.66 & $8.26 * * *$ \\
\hline Current position years & 58702 & 6.01 & 5.67 & 6.13 & $4.82 * * *$ \\
\hline Masters degree & 58702 & 0.37 & & 0.38 & $0.31 * * *$ \\
\hline Doctorate degree & 58702 & 0.02 & & 0.02 & $0.03^{* * *}$ \\
\hline Value Added (Math \& Rdg. avg.) & 13383 & 0.04 & 0.18 & 0.04 & $0.03 * *$ \\
\hline Absences & 58671 & 9.59 & 5.98 & 9.70 & $8.45^{* * *}$ \\
\hline
\end{tabular}

The number of schools fluctuates from year. The mean number in a given year is 366 . Asterisks in rightmost column indicate results of $t$-tests for mean differences with schools with no involuntary transfers, ${ }^{*} \mathrm{p}<.10,{ }^{* *} \mathrm{p}<.05$, ${ }^{* * *} \mathrm{p}$ $<.01$. 
Table 2: Predicting the Likelihood a School Involuntarily Transferred Any Teachers

\begin{tabular}{|c|c|c|}
\hline Variable & $(1)$ & $(2)$ \\
\hline \multicolumn{3}{|l|}{ School Characteristics } \\
\hline School size (in 100s) & $\begin{array}{c}1.216^{* * * *} \\
(0.072)\end{array}$ & $\begin{array}{c}1.256^{* * * *} \\
(0.083)\end{array}$ \\
\hline Percentage free/reduced lunch & $\begin{array}{c}1.172 * * * \\
(0.044)\end{array}$ & $\begin{array}{c}1.196 * * * \\
(0.050)\end{array}$ \\
\hline Percentage Black & $\begin{array}{c}1.060 * * * \\
(0.011)\end{array}$ & $\begin{array}{c}1.072 * * * \\
(0.015)\end{array}$ \\
\hline K-8 school & $\begin{array}{c}10.379 * * * \\
(8.706)\end{array}$ & $\begin{array}{c}18.273 * * * \\
(14.620)\end{array}$ \\
\hline Middle school & $\begin{array}{c}12.132 * * * \\
(8.436)\end{array}$ & $\begin{array}{c}8.533^{* * *} \\
(6.376)\end{array}$ \\
\hline High school & $\begin{array}{c}228.845^{* * * *} \\
(236.479)\end{array}$ & $\begin{array}{c}309.156 * * * \\
(323.382)\end{array}$ \\
\hline 2010 year indicator & $\begin{array}{c}0.173^{* * *} \\
(0.053)\end{array}$ & $\begin{array}{c}0.115^{* * * *} \\
(0.047)\end{array}$ \\
\hline 2011 year indicator & $\begin{array}{c}0.201 * * * \\
(0.070)\end{array}$ & $\begin{array}{c}0.143 * * * \\
(0.063)\end{array}$ \\
\hline Average math and reading score & $\begin{array}{c}0.005^{* * * *} \\
(0.006)\end{array}$ & $\begin{array}{c}0.003^{* * *} \\
(0.004)\end{array}$ \\
\hline \multicolumn{3}{|l|}{ Principal Characteristics } \\
\hline Experience in district (in years) & & $\begin{array}{c}1.016 \\
(0.026)\end{array}$ \\
\hline Current position years & & $\begin{array}{c}0.696 * * * \\
(0.063)\end{array}$ \\
\hline Female & & $\begin{array}{l}0.396 * * \\
(0.166)\end{array}$ \\
\hline Black & & $\begin{array}{c}0.587 \\
(0.303)\end{array}$ \\
\hline Hispanic & & $\begin{array}{c}0.761 \\
(0.481)\end{array}$ \\
\hline Masters degree & & $\begin{array}{c}1.258 \\
(0.847)\end{array}$ \\
\hline Doctorate degree & & $\begin{array}{c}2.007 \\
(1.588)\end{array}$ \\
\hline Specialist degree & & $\begin{array}{c}3.920 \\
(4.301)\end{array}$ \\
\hline Observations & 1043 & 1006 \\
\hline Pseudo R-squared & 0.572 & 0.637 \\
\hline
\end{tabular}


Table 3: Comparison of Schools Sending and Receiving Involuntary Transfers

\begin{tabular}{lcc}
\hline Variable & Sending Schools & Receiving Schools \\
\hline Proportion female students & 0.48 & 0.49 \\
Proportion Black students & 0.72 & $0.32^{* * *}$ \\
Proportion Hispanic students & 0.26 & $0.57^{* * *}$ \\
Proportion subsidized lunch eligible & 0.83 & $0.72^{* * *}$ \\
Proportion limited English proficiency & 0.11 & $0.16^{* * *}$ \\
School size (in 100s) & 11.63 & 12.16 \\
Proportion elementary school & 0.19 & $0.33^{* *}$ \\
Proportion K-8 school & 0.11 & 0.15 \\
Proportion middle school & 0.25 & 0.27 \\
Proportion high school & 0.45 & $0.22^{* * *}$ \\
Standardized math score & -0.51 & $-0.03^{* * *}$ \\
Standardized reading score & -0.56 & $-0.03^{* * *}$ \\
Proportion proficient in math & 0.48 & $0.65^{* * *}$ \\
Proportion proficient in reading & 0.27 & $0.56^{* * *}$ \\
School accountability grade & 2.22 & $4.00^{* * *}$ \\
Student Absences & 11.78 & $7.80^{* * *}$ \\
\hline $\mathrm{N}$ & 73 & 196 \\
\hline Note: Asterisks indicate significant differences from schools that utilized the involuntary transfer policy $(t$-tests), * & &
\end{tabular}


Table 4: Teacher Characteristics by Status in Sending Schools

\begin{tabular}{lllll}
\hline & & Involuntary & Voluntary \\
Variable & Stayers & Transfers & Transfers & Leavers \\
\hline Female & 0.64 & $0.72^{* * *}$ & 0.62 & 0.63 \\
White & 0.35 & $0.22^{* * *}$ & 0.33 & 0.37 \\
Black & 0.49 & $0.59^{* * *}$ & $0.54^{* *}$ & $0.54^{* *}$ \\
Hispanic & 0.12 & 0.14 & 0.10 & $0.06^{* * *}$ \\
Age & 45.21 & 45.65 & $42.55^{* * *}$ & $42.58^{* * *}$ \\
Experience (in years) & 9.45 & 9.43 & $7.21^{* * *}$ & $4.87^{* * *}$ \\
$\quad$ 0 to 1 years & 0.14 & $0.08^{* * *}$ & $0.22^{* * *}$ & $0.53^{* * *}$ \\
$\quad$ 2 to 4 years & 0.26 & $0.32^{* * *}$ & 0.28 & 0.23 \\
$\quad$ 5+ years & 0.60 & 0.60 & $0.50^{* * *}$ & $0.24^{* * *}$ \\
Current position years & 5.75 & $4.82^{* * *}$ & $3.70^{* * *}$ & $2.35^{* * *}$ \\
Bachelors degree & 0.03 & 0.04 & 0.04 & $0.04^{*}$ \\
Masters degree & 0.09 & 0.10 & 0.08 & $0.06^{* * *}$ \\
Doctorate degree & 0.34 & 0.35 & 0.31 & $0.25^{* * *}$ \\
Teach tested subject/grade & 0.18 & $0.35^{* * *}$ & 0.19 & $0.12^{* * *}$ \\
Ever moved to non-tested subject/grade & 0.23 & $0.48^{* * *}$ & $0.29^{* * *}$ & $0.11^{* * *}$ \\
Absences (in days) & 9.05 & $10.73^{* * *}$ & 9.32 & $3.76^{* * *}$ \\
\hline $\mathrm{N}$ & 3786 & 375 & 509 & 742 \\
\hline & & & & \\
Math value-added math (within-school) & 0.09 & $-0.10^{*}$ & 0.03 & -0.04 \\
\hline $\mathrm{N}$ & 381 & 54 & 45 & 39 \\
\hline Reading value-added math (within- & & & & \\
school) & -0.07 & -0.11 & -0.04 & 0.11 \\
\hline $\mathrm{N}$ & 369 & 63 & 56 & 42 \\
\hline
\end{tabular}

Note: Asterisks indicate significant differences from Stayers category $\left(t\right.$-tests). ${ }^{*} \mathrm{p}<.10,{ }^{* *} \mathrm{p}<.05$, $* * * \mathrm{p}<.01$. On average, teachers in Leavers category were only present for about 35 percent of the 180-day school year. 
Table 5: Predicting the Probability of Different Types of Transfer or Exit Next Year

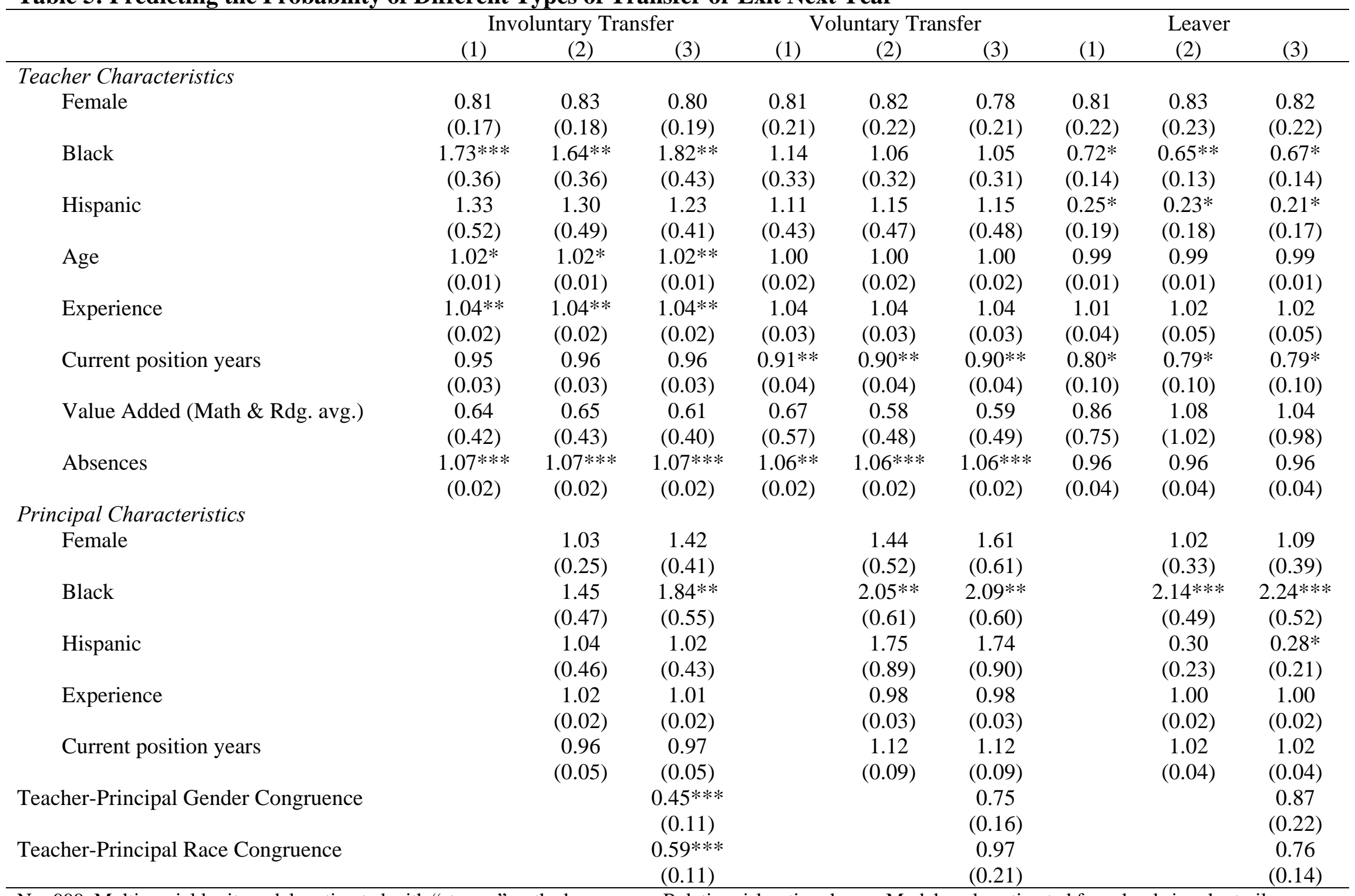

$\mathrm{N}=$ 999. Multinomial logit models estimated with "stayers” as the base group. Relative risk ratios shown. Models only estimated for schools involuntarily transferring at least one teacher. Models also include teacher education level (Masters, doctorate), principal education level (Masters, education specialist, doctorate), year indicator variables, and indicators for school level. Standard errors in parentheses, clustered at school level. $* \mathrm{p}<.10$, $* * \mathrm{p}<.05, * * * \mathrm{p}<.01$. 
Table 6: Comparing Involuntary Transfers to the Teachers Who Replaced Them

\begin{tabular}{lccc}
\hline & Involuntary & & \\
Variable & Transfers & Replacements & New Hires \\
\hline Female & 0.70 & 0.66 & 0.66 \\
Black & 0.58 & 0.50 & $0.49^{* *}$ \\
Hispanic & 0.16 & 0.22 & 0.21 \\
Age & 45.53 & $41.18^{* * *}$ & $42.02^{* * *}$ \\
Experience (in years) & 9.25 & $4.71^{* * *}$ & $5.72^{* * *}$ \\
$\quad$ 0 to 1 years & 0.10 & $0.23^{* * *}$ & $0.29^{* * *}$ \\
$\quad$ 2 to 4 years & 0.33 & 0.42 & 0.36 \\
$\quad$ 5+ years & 0.57 & $0.35^{* * *}$ & $0.35^{* * *}$ \\
Bachelors degree & 0.04 & 0.04 & 0.03 \\
Masters degree & 0.10 & 0.08 & $0.07^{*}$ \\
Doctorate degree & 0.34 & 0.27 & 0.30 \\
Absences (in days) & 10.98 & $8.80^{* * *}$ & $9.11^{* * *}$ \\
\hline $\mathrm{N}$ & 323 & 96 & 408 \\
\hline & & & \\
Math value-added math (within-school) & -0.092 & -0.029 & 0.001 \\
\hline $\mathrm{N}$ & 48 & 14 & 55 \\
\hline Reading value-added math (within-school) & -0.15 & $0.310^{* *}$ & $0.246^{* *}$ \\
\hline $\mathrm{N}$ & 50 & 17 & 50 \\
\hline $\mathrm{N}$
\end{tabular}

Note: Values for involuntary transfer teachers taken for school year preceding the transfer. Values for other two groups taken in the year following the transfer. The teachers in the Replacements category only account for roughly 30 percent of the teachers in the Involuntary Transfers category. The teachers in the Replacements category are also included in the New Hires category. Asterisks indicate significant differences from Involuntary Transfers category, ${ }^{*} \mathrm{p}<.10,{ }^{* *} \mathrm{p}<.05,{ }^{* * *} \mathrm{p}<.01$ 
Table 7: Estimating the Impact of Involuntarily Transfer on Teacher Absences

(1)

(2)

(3)

(4)

(5)

(6)

Teacher Transfer Indicators

Ever involuntary transfer

$\begin{array}{cccccc}1.57^{* * *} & 2.01^{* * *} & 1.58^{* * *} & 2.02^{* * *} & & \\ (0.20) & (0.22) & (0.20) & (0.22) & & \\ -1.15^{* * *} & -1.62^{* * *} & -1.17^{* * *} & -1.62^{* * *} & -1.22^{* * *} & -1.15^{* * *} \\ (0.31) & (0.32) & (0.31) & (0.32) & (0.38) & (0.45) \\ & & 0.35^{* * *} & 0.30^{* * *} & & \\ & & (0.08) & (0.08) & & \\ & & -0.23^{*} & -0.06 & -0.22 & -0.32^{*} \\ & & (0.13) & (0.14) & (0.16) & (0.19)\end{array}$

Teacher Characteristics

Female

$\begin{array}{cccc}1.05^{* * *} & 1.05^{* * *} & 1.06^{* * *} & 1.06 * * * \\ (0.07) & (0.07) & (0.07) & (0.07) \\ -0.18^{* *} & -0.19^{* * *} & -0.18^{* *} & -0.19 * * * \\ (0.07) & (0.07) & (0.07) & (0.07) \\ 0.20^{* * *} & 0.19^{* * *} & 0.20^{* * *} & 0.18^{* * *} \\ (0.07) & (0.07) & (0.07) & (0.07) \\ -0.07 * * * & -0.07^{* * *} & -0.07^{* * *} & -0.07 * * * \\ (0.00) & (0.00) & (0.00) & (0.00) \\ 0.05^{* * *} & 0.05^{* * *} & 0.05^{* * *} & 0.05^{* * *} \\ (0.00) & (0.00) & (0.00) & (0.00) \\ 0.06^{* * *} & 0.05^{* * *} & 0.06^{* * *} & 0.06^{* * *} \\ (0.01) & (0.01) & (0.01) & (0.01) \\ 0.12 * * & 0.12^{* *} & 0.12^{* *} & 0.12^{* *} \\ (0.05) & (0.05) & (0.05) & (0.05)\end{array}$

Doctorate degree

0.06

0.11

0.05

0.11

$(0.22)$

$(0.22)$

(0.22)

$(0.22)$

School Characteristics

School size (in 100s)

$0.02 * * *$

$0.02 * * *$

$0.04 * * *$

$(0.01)$

(0.01)

$(0.01)$

$-0.32$

$-0.33$

$1.08 * * *$

Percentage free/reduced lunch

$(0.23)$

(0.23)

$(0.54)$

$0.70^{*}$

$0.68 *$

0.70

(0.40)

$(0.40)$

(1.01)

Percentage Hispanic students

$0.93^{* *}$

$0.92 * *$

0.14

(0.38)

(0.38)

(1.12)

K-8 school

$-0.09$

(0.08)

$-0.10$

0.33

(0.08)

(0.24)

Middle school

$-0.01$

$-0.03$

0.23

(0.07)

High school

$-1.12 * * *$

(0.07)

(0.28)

$-1.16^{* * *}$

$-0.43$

(0.12)

(0.12)

(0.35) 
Includes school fixed effects

$\begin{array}{llllll}\text { No } & \text { Yes } & \text { No } & \text { Yes } & \text { No } & \text { Yes } \\ \text { No } & \text { No } & \text { No } & \text { No } & \text { Yes } & \text { Yes }\end{array}$

Constant

$9.08 * * *$

9.56***

$9.03^{* * *}$

9.50***

6.89***

Observations

(0.14)

(0.27)

(0.15)

(0.08)

$78234 \quad 78234$

78234

78234

79884

79884

Adjusted R-squared

0.041

0.033

0.033

0.37

Note: Standard errors in parentheses, clustered at teacher level. ${ }^{*} \mathrm{p}<.10, * * \mathrm{p}<.05,{ }^{* * *} \mathrm{p}<.01$. All models include indicator variables for year. Model 6 fit using Stata routine FELSDVREG, which does not estimate a constant or Adjusted $\mathrm{R}^{2}$ statistics. 
Table 8: Test Score Growth for Students Taught by Involuntarily Transferred Teachers

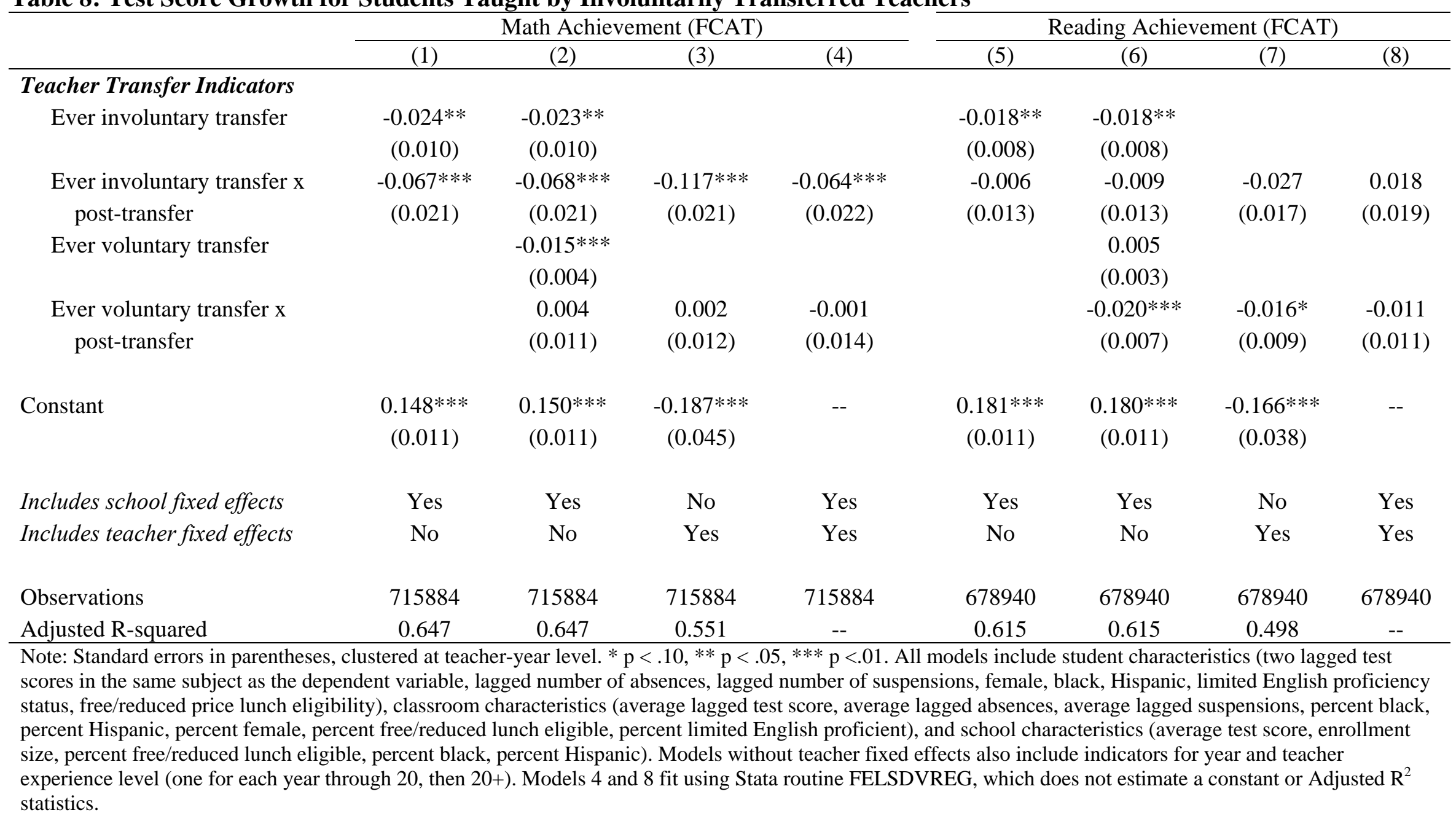


Table 9: Comparing Productivity of Involuntary Transfers to Other New Hires in Receiving Schools

\begin{tabular}{lccc}
\hline & $\begin{array}{c}\text { Math } \\
\text { Achievement } \\
\text { (FCAT) }\end{array}$ & $\begin{array}{c}\text { Reading } \\
\text { Achievement } \\
\text { (FCAT) }\end{array}$ & $\begin{array}{c}\text { Teacher } \\
\text { Absences }\end{array}$ \\
\hline Teacher Transfer Indicators & $(1)$ & $(2)$ & $(3)$ \\
New Hire & & & \\
New Hire x IT x Pre-Transfer & $-0.0134^{* * *}$ & -0.0031 & $0.29^{* * *}$ \\
& $(0.0048)$ & $(0.0040)$ & $(0.09)$ \\
New Hire x IT x Post-Transfer & -0.0107 & $-0.0395^{* * *}$ & $1.58^{* * *}$ \\
& $(0.0209)$ & $(0.0123)$ & $(0.27)$ \\
Constant & $-0.0753^{* * *}$ & $-0.0225^{*}$ & 0.02 \\
& $(0.0193)$ & $(0.0124)$ & $(0.31)$ \\
Observations & $0.1875^{* * *}$ & $0.2190^{* * * *}$ & $9.57^{* * *}$ \\
Adjusted R-squared & $(0.0161)$ & $(0.0156)$ & $(0.19)$ \\
\hline
\end{tabular}

Note: Standard errors in parentheses, clustered at teacher-year (Models 1 and 2) or teacher (Model 3) level. $* \mathrm{p}<.10, * * \mathrm{p}<.05, * * * \mathrm{p}<.01$. All models include school fixed effects and year indicators. Models 1 and 2 include student characteristics (two lagged test scores in the same subject as the dependent variable, lagged number of absences, lagged number of suspensions, female, black, Hispanic, limited English proficiency status, free/reduced price lunch eligibility) and classroom characteristics (average lagged test score, average lagged absences, average lagged suspensions, percent black, percent Hispanic, percent female, percent free/reduced lunch eligible, percent limited English proficient). Model 3 includes teacher characteristics (female, black, Hispanic, age, experience, years in current position, Masters, doctorate). 
Table 10: Predicting the Likelihood of Teaching in an Untested Grade or Subject

\begin{tabular}{cll}
\hline & \multicolumn{1}{c}{$(1)$} & $(2)$ \\
\hline Ever involuntary transfer & 0.89 & $0.80^{*}$ \\
Ever involuntary transfer x post-transfer & $(0.10)$ & $(0.10)$ \\
& $1.79 * * *$ & $2.17^{* * *}$ \\
Teacher Characteristics & $(0.27)$ & $(0.37)$ \\
Female & & \\
& $1.10^{* *}$ & $1.09^{* *}$ \\
Black & $(0.05)$ & $(0.04)$ \\
Hispanic & 1.03 & 1.04 \\
Age & $(0.04)$ & $(0.04)$ \\
District Years & 1.01 & 1.00 \\
Current Job Years & $(0.05)$ & $(0.05)$ \\
Masters Degree & 1.00 & 1.00 \\
& $(0.00)$ & $(0.00)$ \\
Doctorate Degree & $1.02^{* * *}$ & $1.02^{* * *}$ \\
& $(0.00)$ & $(0.00)$ \\
Observations & $0.82^{* * *}$ & $0.82^{* * *}$ \\
\hline Note: Coefficients reported as odds ratios. Standard errors in parentheses. $* \mathrm{p}<.10, * * \mathrm{p}<.05, * * * p$ \\
Model Both models include indicator variables for year. Model 1 controls for school characteristics.
\end{tabular}

